\title{
Modelling transport and deposition of caesium and iodine from the Chernobyl accident using the DREAM model
}

\author{
J. Brandt, J. H. Christensen, and L. M. Frohn \\ National Environmental Research Institute, Department of Atmospheric Environment, Frederiksborgvej 399, P.O. Box 358, \\ DK-4000 Roskilde, Denmark
}

Received: 11 April 2002 - Published in Atmos. Chem. Phys. Discuss.: 24 June 2002

Revised: 9 September 2002 - Accepted: 24 September 2002 - Published: 17 December 2002

\begin{abstract}
A tracer model, DREAM (the Danish Rimpuff and Eulerian Accidental release Model), has been developed for modelling transport, dispersion and deposition (wet and dry) of radioactive material from accidental releases, as the Chernobyl accident. The model is a combination of a Lagrangian model, that includes the near source dispersion, and an Eulerian model describing the long-range transport. The performance of the transport model has previously been tested within the European Tracer Experiment, ETEX, which included transport and dispersion of an inert, non-depositing tracer from a controlled release. The focus of this paper is the model performance with respect to the total deposition of ${ }^{137} \mathrm{Cs},{ }^{134} \mathrm{Cs}$ and ${ }^{131} \mathrm{I}$ from the Chernobyl accident, using different relatively simple and comprehensive parameterizations for dry- and wet deposition. The performance, compared to measurements, of using different combinations of two different wet deposition parameterizations and three different parameterizations of dry deposition has been evaluated, using different statistical tests. The best model performance, compared to measurements, is obtained when parameterizing the total deposition combined of a simple method for dry deposition and a subgrid-scale averaging scheme for wet deposition based on relative humidities. The same major conclusion is obtained for all the three different radioactive isotopes and using two different deposition measurement databases. Large differences are seen in the results obtained by using the two different parameterizations of wet deposition based on precipitation rates and relative humidities, respectively. The parameterization based on subgrid-scale averaging is, in all cases, performing better than the parameterization based on precipitation rates. This indicates that the in-cloud scavenging process is more important than the be-
\end{abstract}

Correspondence to: J. Brandt (jbr@dmu.dk) low cloud scavenging process for the submicron particles and that the precipitation rates are relatively uncertain in the meteorological model compared to the relative humidity. Relatively small differences are, however, seen in the statistical tests between the three different parameterizations of dry deposition.

\section{Introduction}

On 25 April 1986, 21:23 UTC, the world's most serious nuclear accident took place at the Chernobyl nuclear power plant in Ukraine. As a result of two explosions in the power plant a part of the radioactive material was emitted into the atmosphere and transported by the wind to distances thousands of kilometers away from the accident site. Following the Chernobyl accident, many national and international activities have been initiated to develop reliable models that can describe transport and dispersion from a single, but strong source. Such tracer models can be used to estimate the spatial and temporal distribution of the concentrations and depositions of the radioactive material from an accidental release. The output from a tracer model can furthermore be used for warning purposes and to estimate the exposures and the harmful impacts from the dangerous compounds on humans, animals and vegetation.

The use of different instrumentation and sampling methods in the measurements of the concentrations in the period after Chernobyl made it difficult to perform a sufficiently accurate intercomparison and validation of the models in the ATMES report (Atmospheric Transport Model Evaluation Study) (Klug et al., 1992). It became evident that one of the main uncertainties in the model results was due to the un- 
certainty in the emission data and in the parameterization of the deposition processes. A controlled experiment was desirable where these uncertainties were minimized. Therefore an ATMES-II exercise, called ETEX (the European Tracer EXperiment), was initiated in the autumn of 1994. This experiment included two controlled releases, each with a duration of $12 \mathrm{~h}$, of inert, harmless and non-depositing tracer gases (perfluorcarbon compounds) from Brittany, France, and 168 measurement stations throughout Europe. The first release took place in October 1994 (ETEX-1) and the second release about three weeks later in November 1994 (ETEX-2) under comparable meteorological conditions. The evaluation of ETEX-1 ended in the spring of 1997 and included comparisons of results obtained from many different models. Many of the models used the same meteorological data (data from the European Center of Medium range Weather Forecast, ECMWF, with $0.5^{\circ} \times 0.5^{\circ}$ horizontal resolution). The main conclusions from the ETEX evaluation were that the model uncertainties with respect to concentration levels were within a factor of three and within 3-6h with respect to the arrival time of a plume to a specific location (Nodop, 1997; Brandt et al., 1998a). This was the achievable limit of accuracy in long-range transport and dispersion modelling even when the uncertainties connected to the emission rate and the deposition processes were diminished.

Additionally a Nordic intercomparison project, EKO-4 (Emergency Exercises and Information), within the 5th NKS project period (Nordic Nuclear Safety Research in the period 1994-1997) was carried out independent of the European comparison program. The purpose was to perform a "partial functionality test" in which a number of institutions from the Nordic countries participated. The model system, which is described here, has been evaluated and validated both within the ATMES-II/ETEX program (Brandt et al., 1997b; 1998b; Mosca et al., 1997) and within the NKS Nordic intercomparison project (Brandt et al., 1995a, b; 1997a).

Estimates of the emission from the Chernobyl are still very uncertain. However, models have improved since the time of the Chernobyl accident, especially with respect to model resolution due to much more powerful computers. Furthermore, new high quality deposition measurements have become available in the Chernobyl Atlas (De Cort et al., 1998). These measurements, together with measurements from the Radioactivity Environmental Monitoring (REM) database at Ispra have been used in this paper to evaluate the model performance using different parameterizations of wet- and dry deposition. In Sect. 2a general description of the DREAM model is given. In Sect. 3, the source term used in the present simulations is described. Section 4 includes an extensive description of the different parameterizations of wet and dry deposition that are tested in this paper. In Sect. 5 some examples of model results are given, and results from the comparisons of the different parameterizations of wet and dry deposition are given.

\section{The DREAM model}

The tracer model is based on a combination of a Lagrangian meso-scale model (the Ris $\varnothing$ Meso-scale PUFF model, RIMPUFF) and an Eulerian long-range transport model. The combined three-dimensional tracer model is called the DREAM (the Danish Rimpuff and Eulerian Accidental release Model) (Brandt et al., 1995a, b; 1996a, b, c; 1997a, b; 1998a, b; 1999; 2000; Brandt and Zlatev 1998, and Brandt, 1998). The coupling of a Lagrangian model with an Eulerian model, for modelling atmospheric transport and dispersion from point sources, has been carried out due to both numerical and physical arguments. Numerical treatment of the advection of air pollutants from a single source is not a simple problem. The traditional Eulerian models have problems with sharp gradients from a single strong source. The sharp gradients cause unwanted oscillations, also known as Gibbs phenomena. Lagrangian models have, however, problems with uncertainties in the trajectory calculations on long range, due to exponentially increasing errors. Furthermore, the K-theory, which is usually applied for the description of dispersion in Eulerian models, is unsatisfactory near to the source. The basic idea of coupling two models in DREAM is to gain advantage of both types of models. The Lagrangian model is used in the area near the source to calculate the initial transport and dispersion of the release. The Eulerian model is used for long-range transport calculations in the whole model domain that, in the present work, covers all of Europe and parts of Asia and Africa. The numerical performance of the coupled model is described in Brandt et al. (1996a).

The model is applied on a polar stereographic projection with a spatial resolution of $25 \mathrm{~km} \times 25 \mathrm{~km}$ in the Eulerian model and $5 \mathrm{~km} \times 5 \mathrm{~km}$ in the Lagrangian model. The number of grid points in the two domains are $192 \times 192$ and $105 \times 105$, respectively and the model has 16 vertical ?-levels. The depth of the lowest layer is approximately $80 \mathrm{~m}$.

In order to obtain a more precise description of the mean meteorological fields, the meteorological meso-scale model MM5V1 (Grell et al., 1995) is used as a meteorological driver for the transport model. Coupling DREAM with a meteorological driver increases the computing time considerably, but improves the quality of the meteorological data significantly (Brandt et al., 1998a). Different parameterizations of vertical dispersion, mixing height and different meteorological input data used in the model is described and their performance with respect to ETEX is tested in Brandt et al., (1998a).

\subsection{The Eulerian model}

Advective transport, dispersion, emission, wet deposition and radioactive decay are described in the Eulerian mod- 
elling framework by the equation:

$$
\begin{aligned}
\frac{\partial C}{\partial t} & =-\left(u \frac{\partial C}{\partial x}+v \frac{\partial C}{\partial y}+\dot{\sigma} \frac{\partial C}{\partial \sigma}\right) \\
& +K_{x} \frac{\partial^{2} C}{\partial x^{2}}+K_{y} \frac{\partial^{2} C}{\partial y^{2}}+\frac{\partial}{\partial \sigma}\left(K_{\sigma} \frac{\partial C}{\partial \sigma}\right) \\
& +E(x, y, \sigma, t) \\
& -\Lambda C-k_{r} C
\end{aligned}
$$

where $C$ is the specific activity field, $u$ and $v$ are the wind speed components in the $x$ and $y$ directions respectively, and $\dot{\sigma}$ is the vertical motion in the $\sigma$ coordinate system. $K_{x}, K_{y}$, $K_{\sigma}$ are the eddy diffusion coefficients. The horizontal dispersion in the Eulerian model is set constant $\left(K_{x}=K_{y}=\right.$ $\left.10000 \mathrm{~m}^{2} \mathrm{~s}^{-1}\right)$. $E(x, y, \sigma, t)$ is the emission term, $\Lambda$ is the scavenging coefficient for wet deposition and $k_{r}$ is representing the radioactive decay $\left(k_{r}=\log (2) /\right.$ half life $)$. For ${ }^{131} \mathrm{I}$ the half-life is 8.02070 days, for ${ }^{134} \mathrm{Cs}$ it is 2.0648 years and for ${ }^{137} \mathrm{Cs}$ it is 30.07 years. Radioactive decay of ${ }^{134} \mathrm{Cs}$ and ${ }^{137} \mathrm{Cs}$ is not important for short-term simulations and is therefore excluded in the present work. Dry deposition is represented by the term $-v_{d} C$, which in practice is applied as a lower boundary condition in the vertical dispersion. The vertical discretization in the model system is in $\sigma$-coordinates and defined by the pressure, $P$, normalized by the surface pressure as $\sigma=\left(P-P_{t}\right) /\left(P_{s}-P_{t}\right)$, where $P_{t}=100 \mathrm{hPa}$ is the pressure at the top of the model domain and $P_{S}$ is the surface pressure.

Equation (1) is solved using the fractional steps method. The model has been split into three sub-models (Brandt and Zlatev, 1998) including: 1) three-dimensional advection, horizontal dispersion and emission, 2) vertical dispersion and dry deposition, and 3) wet deposition and radioactive decay. The treatment of the advection and dispersion in the Eulerian model is performed using a finite element algorithm. This algorithm has been tested against several other advection algorithms using the well-known Molenkamp-Crowley rotation test (Brandt et al., 1996a,d). The finite element scheme is a relatively fast scheme. This is important when used operationally. A predictor-corrector algorithm with three correctors has been used for time integration of the first sub-model (Zlatev, 1995). Time integration in the second sub-model is solved using the less expensive and more stable $\theta$-method (Christensen, 1997) and the third sub-model is solved directly.

\subsection{The Lagrangian model}

The Lagrangian model, which has been implemented into the Eulerian model, is a puff model, which simulates a release changing in time by sequentially releasing a series of Gaussian shaped puffs. In the vertical the Gaussian shape has been transformed into $\sigma$-coordinates, using the hydrostatic approximation and the ideal gas law. Each puff is advected and dispersed individually along trajectories. The specific activity field $C_{x, y, \sigma}$ in $\sigma$-coordinates at a point $(x, y, \sigma)$, is given by the sum of the contributions from the total number of puffs, $N$, as

$$
\begin{aligned}
& C_{x, y, \sigma}=\sum_{i=1}^{N} \frac{M_{i} g\left(\sigma_{c_{i}}+\phi\right)}{(2 \pi)^{3 / 2} \tilde{\sigma}_{x y_{i}}^{2} \tilde{\sigma}_{\sigma_{i}} \rho R \overline{T_{v}}} \\
& x \exp \left(-\frac{1}{2}\left(\left(\frac{x-x_{c_{i}}}{\tilde{\sigma}_{x y_{i}}}\right)^{2}+\left(\frac{y-y_{c_{i}}}{\tilde{\sigma}_{x y_{i}}}\right)^{2}\right)\right) \\
& x\left(\begin{array}{l}
\exp \left(-\frac{1}{2}\left(\frac{\sigma_{c_{i}}+\phi}{\tilde{\sigma}_{\sigma_{i}}} \ln \left(\frac{\psi_{c_{i}}}{\psi}\right)\right)^{2}\right) \\
+\exp \left(-\frac{1}{2}\left(-\frac{\sigma_{c_{i}}+\phi}{\tilde{\sigma}_{\sigma_{i}}} \ln \left(\psi \psi_{c_{i}}\right)\right)^{2}\right) \\
+\exp \left(-\frac{1}{2}\left(\frac{\sigma_{c_{i}}+\phi}{\tilde{\sigma}_{c_{i}}} \ln \left(\frac{\psi_{c_{c_{i}}}}{2 \psi_{H_{m i x}}}\right)\right)^{2}\right)
\end{array}\right)
\end{aligned}
$$

where $M_{i}$ is the mass of the air pollutant in a given puff. $\tilde{\sigma}_{x y_{i}}$ and $\tilde{\sigma}_{\sigma_{i}}$ are the standard deviations of the puff $i$ and a measure for the puff size in horizontal and vertical directions respectively. $\phi$ is given by $\phi=P_{t} / P^{*}, P^{*}=P_{s}-P_{t}$. The coordinate of the puff's center of mass is given by $\left(x_{c_{i}}, y_{c_{i}}, \sigma_{c_{i}}\right) . T_{v}$ is the virtual temperature, $\rho$ is the density of air, $R$ is the gas constant for dry air, and $g$ is the acceleration due to gravity. The functions $\psi, \psi_{c_{i}}$ and $\psi_{H_{m i x}}$ represents the height, the height of the puff center and the mixing height, respectively and are defined as

$\psi=\frac{\sigma P^{*}+P_{t}}{P_{s}}$
$\psi_{c_{i}}=\frac{\sigma_{c_{i}} P^{*}+P_{t}}{P_{s}}$
$\psi_{H_{m i x}}=\frac{\sigma_{H_{m i x}} P^{*}+P_{t}}{P_{s}}$

(3) where $\sigma_{H_{m i x}}$ is the mixing height in $\sigma$-coordinates. The first term on the right hand side of Eq. (2) represents the maximum specific activity in the center of a puff. The second and third term represents the horizontal and vertical distribution of the concentrations. The last two terms of the vertical distribution are the reflection due to the ground and to the top of the mixed layer $H_{\text {mix }}$. The two terms represent two artificial sources: One below the ground and one above the mixing height. If the vertical standard deviation $\tilde{\sigma}_{\sigma_{i}}$ is greater than twice the mixing height then further artificial sources are needed. In order to avoid a large number of exponential functions in the expression, total vertical mixing inside the mixed layer is then assumed and Eq. (2) reduces to

$$
\begin{gathered}
C_{x, y, \sigma}=\sum_{i=1}^{N} \frac{M_{i} g\left(\sigma_{c_{i}}+\phi\right)}{2 \pi \tilde{\sigma}_{x y_{i}}^{2} \rho R T_{v}} \\
x \exp \left(-\frac{1}{2}\left(\left(\frac{x-x_{c_{i}}}{\tilde{\sigma}_{x y_{i}}}\right)^{2}+\left(\frac{y-y_{c_{i}}}{\tilde{\sigma}_{x y_{i}}}\right)^{2}\right)\right) \\
x\left(\left(\sigma_{c_{i}}+\phi\right)\left(-\ln \left(\psi_{H_{m i x}}\right)\right)\right)^{-1}
\end{gathered}
$$


2.3 Numerical treatment of deposition and radioactive decay in the Lagrangian model

The mass loss, $\Delta M_{l}$, for a puff, $l$, within the layer $z$ due to dry deposition in the Lagrangian puff model is assumed to be a sum of the mass losses in the horizontal grid-cells, $(i, j)$, that are covered by the puff, in the lowest model layer

$$
\Delta M_{l}=\sum_{j=1}^{J} \sum_{i=1}^{I} M_{l, i, j}\left(1-e^{-\Delta t \frac{{ }^{v} d_{i, j}}{z}}\right)
$$

where $z$ is the height of the lowest model layer. $I$ and $J$ are the total number of horizontal grid-cells in the lowest model layer, covered by the puff in the $x$ and $y$ directions, respectively. $\Delta t$ is the time step and $v_{d}$ is the dry deposition velocity.

The mass loss due to wet deposition and radioactive decay is described in a similar way, but here the summation is performed over all grid-cells in all three dimensions, $(i, j, k)$, that are covered by the puff

$\Delta_{M_{l}}=\sum_{k=1}^{K} \sum_{j=1}^{J} \sum_{i=1}^{I} M_{l, i, j, k}\left(1-e^{-\Delta t_{\left(\Lambda_{i, j, k}+k_{r}\right)}}\right)$

where $K$ is the number of levels covered by the puff.

The new mass in the individual puff is found by subtracting the total contributions from dry- and wet deposition and radioactive decay. A new specific activity field can now be found by inserting the new puff masses in the calculation of the specific activities in Eqs. (2) and (4).

\section{Source data from the Chernobyl accident}

The location of Chernobyl is $\mathrm{N} 51^{\circ} 17^{\prime} \mathrm{E} 30^{\circ} 15^{\prime}$. The emission data from the Chernobyl accident are not known precisely. The emissions were temporally highly variable. Furthermore, due to the high temperature of the melting core (up to approximately $2000^{\circ} \mathrm{C}$ ), the material was assumed to reach heights up to $2000 \mathrm{~m}$ and even more. Thus, information about the emission rates and emission heights account for a very large uncertainty when simulating the transport and dispersion from the Chernobyl accident. The first estimation of the source term was mainly based on a USSR report to the International Atomic Energy Agency (IAEA) in 1986 (Persson et al., 1986; Hass et al., 1990), where the source was estimated on the basis of summation of the material deposited within the countries of the former USSR. These investigations did not take into account the material deposited outside the former USSR and has since been corrected several times from other investigations with more than a factor of two.

The source term used in these simulations (see Table 1) was last revised in November 1995 in an OECD/NEA report (Waight et al., 1995). Still, the uncertainty of the source term has been estimated to at least $\pm 50 \%$. The amount of release and temporal variation used in this study is taking from Devell et al. (1995) and similar to the estimates in De Cort et al. (1998). The effective height of the release as a function of time is taken from Persson et al. (1986) and is also used in e.g. Hass et al. (1990). The total activity of all the radioactive material released in the accident is estimated to have been around $12 \times 10^{18} \mathrm{~Bq}$. The radionuclide composition of the material released in the accident was very complex and consisted of various isotopes of $\mathrm{Xe}, \mathrm{I}, \mathrm{Cs}, \mathrm{Te}, \mathrm{Sr}, \mathrm{Ba}, \mathrm{Zr}$, Mo, $\mathrm{Ru}, \mathrm{Ce}, \mathrm{Np}, \mathrm{Pu}$ and $\mathrm{Cm}$, with radioactive half-lives in the range of hours (e.g. ${ }^{95} \mathrm{Zr}$ ) to thousands of years (e.g. ${ }^{239} \mathrm{Pu}$ ). The radioactive isotopes of iodine and caesium were of the greatest significance. Iodine with its short radioactive halflive had the greater radiological impact in the short term, and caesium with a half-live of 30 years has the greater radiological impact in the long term.

In the latest revision, the total emission of ${ }^{137} \mathrm{Cs}$ during the release, was estimated to $85 \times 10^{15} \mathrm{~Bq}$, for ${ }^{134} \mathrm{Cs}$ it was estimated to $54 \times 10^{15} \mathrm{~Bq}$ and for ${ }^{131} \mathrm{I}$ to $1.76 \times 10^{18} \mathrm{~Bq}$, corresponding to $30 \%, 30 \%$ and $55 \%$ of the total core inventory of $280 \times 10^{15} \mathrm{~Bq}, 180 \times 10^{15}$ and $3.2 \times 10^{18} \mathrm{~Bq}$, respectively (De Cort et al., 1998). The daily fraction of the total release is largest in the beginning and in the end of the 10 days period of the major release (see Table 1). The initial large release was due to the mechanical fragmentation of the fuel during the initial two explosions. It contained mainly the more volatile radionuclides such as noble gases, iodine and some caesium. The second large release in the end was associated with the high temperatures reached in the core melt (Waight et al., 1995).

\section{Parameterizations of dry- and wet deposition}

The term deposition refers to the transfer of airborne material, both gaseous and particles, to the surface of the earth, including soil, water and vegetation by wet and dry removal processes. Deposition is, however, very difficult to parameterize because deposition of a certain compound depends on boundary layer meteorology, landuse data (different kinds of vegetation, water, soil, etc.), the characteristics of the compound (as e.g. whether it is in gaseous or in particulate form, or both) and on the three-dimensional cloud physics (precipitation rates). Deposition is also a strongly time varying function with an annual variation due to the dependence on vegetation type (with or without leaves, etc.) as well as a diurnal variation due to meteorological conditions and vegetational variation (diurnal variation of stomata). Furthermore there is a stochastic variation due to precipitation.

The deposition process of the three species, ${ }^{131} \mathrm{I},{ }^{134} \mathrm{Cs}$ and ${ }^{137} \mathrm{Cs}$, which are treated here in connection with the Chernobyl accident, is not fully understood. The caesium isotopes, ${ }^{134} \mathrm{Cs}$ and ${ }^{137} \mathrm{Cs}$, are in their particulate form, when released from a nuclear power plant, but the particle size distribution from e.g. the Chernobyl accident is a very uncertain 
Table 1. Release rates in Bq/day and relative distribution of material released in different heights of ${ }^{137} \mathrm{Cs}$, ${ }^{134} \mathrm{Cs}$ and ${ }^{131} \mathrm{I}$ in the period of the release, according to Hass et al. (1990), Devell et al. (1995), Waight et al., (1995) and De Cort et al. (1998). Figures in parentheses are the daily release fraction of the total release.

\begin{tabular}{|c|c|c|c|c|c|c|}
\hline $\begin{array}{l}\text { Approximate } \\
\text { height [m] }\end{array}$ & Species & $\begin{array}{l}\text { 25-26 April } \\
(23.8 \%)\end{array}$ & $\begin{array}{l}27 \text { April } \\
(7.9 \%)\end{array}$ & $\begin{array}{l}28 \text { April } \\
(6.9 \%)\end{array}$ & $\begin{array}{l}29 \text { April } \\
(4.8 \%)\end{array}$ & $\begin{array}{l}30 \text { April } \\
(4 \%)\end{array}$ \\
\hline \multirow[t]{3}{*}{225} & ${ }^{137} \mathrm{Cs}$ & - & - & $2.9 \times 10^{15}$ & $2.0 \times 10^{15}$ & $1.7 \times 10^{15}$ \\
\hline & ${ }^{134} \mathrm{Cs}$ & - & - & $1.9 \times 10^{15}$ & $1.3 \times 10^{15}$ & $1.1 \times 10^{15}$ \\
\hline & ${ }^{131} \mathrm{I}$ & - & - & $6.1 \times 10^{16}$ & $4.2 \times 10^{16}$ & $3.5 \times 10^{16}$ \\
\hline \multirow[t]{3}{*}{425} & ${ }^{137} \mathrm{Cs}$ & - & $6.7 \times 10^{14}$ & $2.9 \times 10^{15}$ & $2.0 \times 10^{15}$ & $1.7 \times 10^{15}$ \\
\hline & ${ }^{134} \mathrm{Cs}$ & - & $4.3 \times 10^{14}$ & $1.9 \times 10^{15}$ & $1.3 \times 10^{15}$ & $1.1 \times 10^{15}$ \\
\hline & ${ }^{131} \mathrm{I}$ & - & $1.4 \times 10^{16}$ & $6.1 \times 10^{16}$ & $4.2 \times 10^{16}$ & $3.5 \times 10^{16}$ \\
\hline \multirow[t]{3}{*}{715} & ${ }^{137} \mathrm{Cs}$ & - & $3.4 \times 10^{15}$ & - & - & - \\
\hline & ${ }^{134} \mathrm{Cs}$ & - & $2.1 \times 10^{15}$ & - & - & - \\
\hline & ${ }^{131} \mathrm{I}$ & - & $7.0 \times 10^{16}$ & - & - & - \\
\hline \multirow[t]{3}{*}{1090} & ${ }^{137} \mathrm{Cs}$ & $1.0 \times 10^{16}$ & $2.7 \times 10^{15}$ & - & - & - \\
\hline & ${ }^{134} \mathrm{Cs}$ & $6.4 \times 10^{15}$ & $1.7 \times 10^{15}$ & - & - & - \\
\hline & ${ }^{131} \mathrm{I}$ & $2.1 \times 10^{17}$ & $5.6 \times 10^{16}$ & - & - & - \\
\hline \multirow[t]{3}{*}{1575} & ${ }^{137} \mathrm{Cs}$ & $8.1 \times 10^{15}$ & - & - & - & - \\
\hline & ${ }^{134} \mathrm{Cs}$ & $5.1 \times 10^{15}$ & - & - & - & - \\
\hline & ${ }^{131} \mathrm{I}$ & $1.7 \times 10^{17}$ & - & - & - & - \\
\hline \multirow[t]{3}{*}{2225} & ${ }^{137} \mathrm{Cs}$ & $2.0 \times 10^{15}$ & - & - & - & - \\
\hline & ${ }^{134} \mathrm{Cs}$ & $1.3 \times 10^{15}$ & - & - & - & - \\
\hline & ${ }^{131} \mathrm{I}$ & $4.2 \times 10^{16}$ & - & - & - & - \\
\hline \multirow[t]{3}{*}{225} & ${ }^{137} \mathrm{Cs}$ & $1.7 \times 10^{15}$ & $3.4 \times 10^{15}$ & $4.3 \times 10^{15}$ & $6.1 \times 10^{15}$ & $7.0 \times 10^{15}$ \\
\hline & ${ }^{134} \mathrm{Cs}$ & $1.1 \times 10^{15}$ & $2.1 \times 10^{15}$ & $2.7 \times 10^{15}$ & $3.9 \times 10^{15}$ & $4.4 \times 10^{15}$ \\
\hline & ${ }^{131} \mathrm{I}$ & $3.5 \times 10^{16}$ & $7.0 \times 10^{16}$ & $8.8 \times 10^{16}$ & $1.3 \times 10^{17}$ & $1.4 \times 10^{17}$ \\
\hline \multirow[t]{3}{*}{425} & ${ }^{137} \mathrm{Cs}$ & $1.7 \times 10^{15}$ & $3.4 \times 10^{15}$ & $4.3 \times 10^{15}$ & $6.1 \times 10^{15}$ & $7.0 \times 10^{15}$ \\
\hline & ${ }^{134} \mathrm{Cs}$ & $1.1 \times 10^{15}$ & $2.1 \times 10^{15}$ & $2.7 \times 10^{15}$ & $3.9 \times 10^{15}$ & $4.4 \times 10^{15}$ \\
\hline & ${ }^{131} \mathrm{I}$ & $3.5 \times 10^{16}$ & $7.0 \times 10^{16}$ & $8.8 \times 10^{16}$ & $1.3 \times 10^{17}$ & $1.4 \times 10^{17}$ \\
\hline
\end{tabular}

Table 2. Different typical values for dry deposition velocities of ${ }^{131} \mathrm{I}$ and ${ }^{137} \mathrm{Cs}$ from different publications

\begin{tabular}{lll}
\hline Source & \multicolumn{2}{c}{ Dry deposition velocities } \\
& ${ }^{131} \mathrm{I}[\mathrm{cm} / \mathrm{s}]$ & ${ }^{137} \mathrm{Cs}[\mathrm{cm} / \mathrm{s}]$ \\
\hline Hanna (1991) & 0.3 & 0.1 \\
Maryon et al. (1991) & 0.5 & 0.05 \\
Klug et al. (1992) & $0.15-2.0$ & $0.1-0.5$ \\
Slinn et al. (1978) & - & $0.31($ water 0.9) \\
Sehmel (1980) & $0.1-2.0$ & $0.04-0.5($ water 0.09$)$ \\
\hline
\end{tabular}

factor (ranging from $0.01 \mu \mathrm{m}$ to more than $50 \mu \mathrm{m}$, (Valkama and Pöllänen, 1996; Valkama et al., 1995). ${ }^{131}$ I is released in its gaseous form, but tends to attach to other particles as e.g. sulphur (Maryon et al., 1991). The effective dry deposition velocity for ${ }^{131} \mathrm{I}$ therefore tends to decrease with time. The typical time scale for this depletion from gaseous to particulate form is, however, large (about 47 days (Maryon et al., 1991)) compared to the length of the model simulation (12 days in this study), so this effect is not taken into account here. Because of these uncertainties, both comprehensive and simple parameterizations of wet- and dry deposition are tested in this study.

Typical values of dry deposition velocities used in different publications for simulations of the Chernobyl accident show quite large differences. Some typical values, which have been used in different publications, for dry deposition velocities for ${ }^{131} \mathrm{I}$ and ${ }^{137} \mathrm{Cs}$ are shown in Table 2 . The values vary with more than one order of magnitude.

The change in the air specific activity field due to dry deposition is calculated using the flux $F$ from the air to the 
surface and is applied as a lower boundary condition for the vertical dispersion in the Eulerian model and is proportional to the specific activity $C$

$F=v_{d} C$

The deposition velocity is usually given in $z$-coordinates. In $\sigma$-coordinates $v_{d}$ is rewritten to (assuming hydrostatic approximation)

$v_{d}(\sigma)=\frac{\partial \sigma}{\partial z} v_{d}(z)=\left(\frac{\rho g}{P_{*}}\right) v_{d}(z)$

The wet deposition of material is based on the equation

$\frac{d C}{d t}=-\Lambda C$

where $\Lambda$ is the scavenging coefficient.

In the following sections, a description of the different parameterizations of dry and wet deposition, used in the model and tested against measurements using different statistics (Sect. 6) are given. The first two dry deposition schemes are based on the resistance method for both gaseous compounds and particles (in the tables referred to as "resistance, gas" and "resistance, particle"). The second is based on a simple parameterization of dry deposition based on the friction velocity and Monin-Obukhov length (referred to as "simple"). These schemes are compared to the very simple case of a constant deposition velocity of $0.2 \mathrm{~cm} \mathrm{~s}^{-1}$ (referred to as "constant"). For wet deposition, two different schemes are tested; one based on precipitation rates, and one based on relative humidity.

4.1 Dry deposition of gaseous compounds based on the resistance method

Dry deposition is usually parameterized by an analogy to electrical or heat flow through a series of resistances. The transfer of material from the atmosphere to the surface is assumed to take place through three resistances: the aerodynamic resistance (in some contexts also called the atmospheric resistance), $r_{a}$, the quasi-laminar layer resistance (or the deposition layer resistance), $r_{b}$, and the canopy resistance (also called the transfer resistance or the vegetation layer resistance or the surface layer resistance), $r_{c}$.

The dry deposition velocity, $v_{d}$, is for gaseous compounds given at the reference height $z$, as a function of the resistances (see e.g. Seinfeld, 1986)

$v_{d}=\frac{1}{r_{a}+r_{b}+r_{c}}$

The aerodynamic resistance represents the efficiency of turbulent transport of the material to the laminar surface layer. Parameterization of the aerodynamic resistance $r_{a}$ is given by (Wesely and Hicks, 1977; see also Voldner et al., 1986; Hanna, 1991; Maryon et al., 1996)

$r_{a}=\frac{1}{k u_{*}}\left(\ln \left(\frac{z}{z_{0}}\right)-\Phi_{h}\left(\frac{z}{L}\right)\right)$ where $\Phi_{h}$ is a stability correction function, given by

$$
\begin{aligned}
\Phi_{h} & =-5 \frac{z}{L}, \quad \frac{z}{L}>0(\text { stable }) \\
\Phi_{h}=\exp \left[0.598+0.390 \ln \left(-\frac{z}{L}\right)\right. & \left.-0.090\left(\ln \left(-\frac{z}{L}\right)\right)^{2}\right], \\
\frac{z}{L} & <0(\text { unstable })
\end{aligned}
$$

The quasi-laminar resistance $r_{b}$ is used to specify the resistance to transport across the thin quasi-laminar layer over the surface layer. For gaseous compounds, it is parameterized by (see e.g. Hanna, 1991, or Maryon et al., 1996)

$r_{b}=\frac{2}{0.72^{2 / 3} k u_{*}} S c^{2 / 3}$

$S c$ is the Schmidt number

$S c=\frac{v}{D}$

where $v$ is the kinematic viscosity of air, $(v=\mu / \rho \approx$ $1.5 \times 10^{-5} \mathrm{~m}^{2} \mathrm{~s}^{-1}$ ) and $D$ is the molecular (Brownian) diffusivity of the pollutant given as a function of the particle or molecular diameter $D_{p}$ (Seinfeld, 1986; Landau and Lifshitz, 1987).

$D=\frac{k_{B} T C u}{6 \pi \mu D_{p}}$

where $k_{B}$ is the Boltzmann constant $\left(k_{B}=1.38 \times\right.$ $\left.10^{-23} \mathrm{~J} \mathrm{~K}^{-1}\right), T$ is the temperature and $\mu$ is the dynamic viscosity coefficient $\left(\sim 1.8 \times 10^{-5} \mathrm{~kg} \mathrm{~m}^{-1} \mathrm{~s}^{-1}\right)$. The diameter of iodine molecules in gaseous form is set to $2.8 \times 10^{-10} \mathrm{~m}$ (Forsythe, 1956). $\mathrm{Cu}$ is the Cunningham correction for small particles or molecules (less than $1 \mu \mathrm{m}$ ) and is given by (Seinfeld, 1986)

$C u=1+\frac{\lambda}{D_{p}}\left(2.514+0.80 \exp \left(-\frac{0.55 D_{p}}{\lambda}\right)\right)$

where $\lambda=6.53 \times 10^{-8} \mathrm{~m}$ is the mean free path of air molecules at standard temperature $(293.15 \mathrm{~K})$ and standard pressure $(1013.25 \mathrm{hPa})$.

The surface resistance, $r_{c}$, characterizes the resistance to capture the species by the surface itself. It depends on the specific pollutant and on the different landuse categories. It is the most difficult parameter to estimate. It is appropriate to apply a value for each landuse category. Some preliminary experiments were carried out, where it has been assumed that the magnitude of $r_{c}$ for iodine is similar to sulphur dioxide for the different landuse categories (see e.g. Sheih et al., 1979; Voldner et al., 1986). Little research has, however, been carried out in this field for the radioactive compound, iodine, and given the lack of experimental data and the uncertainties in determining the surface resistance for this species a fixed value of $r_{c}$ has been used. Chamberlain and Chadwick (1966) or Verver and De Leeuw (1992) recommend $r_{c} \approx 500 \mathrm{~s} / \mathrm{m}$ for ${ }^{131} \mathrm{I}$. 
Table 3. Constants $A$ and $B$ used to calculate the scavenging coefficients, based on precipitation rates (Maryon et al., 1996)

\begin{tabular}{|c|c|c|c|c|}
\hline & \multicolumn{2}{|c|}{ Rain $\left[s^{-1}\right]$} & \multicolumn{2}{|c|}{ Snow $\left[\mathrm{s}^{-1}\right]$} \\
\hline & Convective & Dynamic & Convective & Dynamic \\
\hline $\begin{array}{l}\text { Washout below } \\
\text { cloud base }\end{array}$ & \multicolumn{2}{|c|}{$\begin{array}{c}A=8.4 \times 10^{-5} \\
B=0.79\end{array}$} & \multicolumn{2}{|c|}{$\begin{array}{c}A=8.0 \times 10^{-5} \\
B=0.305\end{array}$} \\
\hline $\begin{array}{l}\text { Rainout between } \\
\text { cloud base and top }\end{array}$ & $\begin{array}{l}A=3.36 \times 10^{-4} \\
B=0.79\end{array}$ & $\begin{array}{l}A=8.4 \times 10^{-5} \\
B=0.79\end{array}$ & $\begin{array}{l}A=3.36 \times 10^{-4} \\
B=0.79\end{array}$ & $\begin{array}{l}A=8.0 \times 10^{-5} \\
B=0.305\end{array}$ \\
\hline
\end{tabular}

4.2 Dry deposition of particulate compounds based on the resistance method

Particulate matter (as e.g. ${ }^{134} \mathrm{Cs}$ and ${ }^{137} \mathrm{Cs}$ ) does not interact with vegetation in the same way as gaseous compounds. The canopy resistance is not taken into account because once penetrating the quasi-laminar layer the particles are usually assumed to stick to the surface. The deposition velocity for particles can be expressed as (see e.g. Hanna et al., 1991; Seinfeld, 1986)

$v_{d}=\frac{1}{r_{a}+r_{b}+r_{a} r_{b} v_{g}}+v_{g}$

where $v_{g}$ is the gravitational settling velocity of the particles given by Stokes equation (Hanna et al., 1991)

$v_{g}=\frac{D_{p}^{2} g\left(\rho_{p}-\rho\right) C u}{18 v}$

where $\rho$ is the density of air and $\rho_{p}$ is the particle density $\left(1.88 \mathrm{~g} / \mathrm{cm}^{3}\right.$ for caesium (Weast and Astle, 1980)). The distribution of the particle diameters of the radioactive species, which are treated here, is an unknown factor. $D_{p}$ is therefore set constant and different scenarios have been performed with different particle diameters in the range from $0.1 \mu \mathrm{m}$ to $10 \mu \mathrm{m}$. In the calculations included here, $D_{p}=1 \mu \mathrm{m}$ has been chosen as a representative particle diameter.

For particles $r_{b}$ is parameterized in terms of the Schmidt number and the Stokes number, $S t$

$r_{b}=\frac{1}{u_{*}\left(S c^{-2 / 3}+10^{-3 / S t}\right)}$

where the Stokes number, or impact parameter, a measure of the probability of particle collisions, is given by

$S t=\frac{v_{g} u_{*}^{2}}{g v}$

\subsection{A simple parameterization of dry deposition}

The dry deposition velocity can be parameterized in a simple way based on two important boundary layer parameters: the friction velocity $u *$ and the Monin-Obukhov length, $L$. The following expression is obtained from Seland et al. (1995)

$$
\begin{aligned}
& v_{d}=\frac{u *}{a}, \quad L>0 \\
& v_{d}=\frac{u *}{a}\left(1+\left(\frac{300}{-L}\right)^{2 / 3}\right), \quad L<0
\end{aligned}
$$

where $a=500$ for low vegetation and a=100 for forest. This parameterization is denoted "simple" in the comparison studies in Sect. 5.

\subsection{Wet deposition based on precipitation rates}

The washout of air pollutants by precipitation is basically dependent on the precipitation rate (in three dimensions) and type of precipitation. The scavenging coefficient is in this scheme defined as (Maryon et al., 1996)

$\Lambda=A r^{B}$

where $r$ is the precipitation rate (in $\mathrm{mm} /$ hour) and $A$ and $B$ are constants, which are dependent on the type of precipitation. Values for $A$ and $B$ (given in Table 3) are determined for convective and non-convective (dynamic) precipitation and depend on whether the temperature is above or below freezing level. Information on whether the precipitation is convective or non-convective is included in the model results from the MM5V1 model.

The coefficients given in Table 3 , are of the same order of magnitude as those used in e.g. ApSimon et al. (1988), where $A=10^{-4}$ and $B=0.8$ are recommended.

\subsection{Wet deposition based on subgrid-scale averaging}

In some cases, when information about the precipitation rate is not available or uncertain, a more simple parameterization for $\Lambda$ can be used. This simple scheme, which is called the subgrid-scale averaging scheme is based on the relative humidity, $R H$, where the scavenging coefficients are calculated from (Pudykiewicz, 1989):

$$
\begin{aligned}
& \Lambda=0, \quad R H<R H_{t} \\
& \Lambda=3.5 \times 10^{-5}\left(\frac{R H-R H_{t}}{R H_{s}-R H_{t}}\right), \quad R H \geq R H_{t}
\end{aligned}
$$


$R H_{t}(=80 \%)$ is the threshold value of the relative humidity from which the subgrid scale condensation can be initiated, $R H_{S}(=100 \%)$ is the saturation value. The term $\left(R H-R H_{t}\right) /\left(R H_{s}-R H_{t}\right)$ is the fractional cloud cover as defined by Sundqvist (1981). $\lambda \mathrm{a}=3.5 \times 10^{-5}$ is the typical in-cloud scavenging rate for submicron particles estimated assuming average cloud water content of precipitating clouds. The rationale for selecting this value of $\lambda \mathrm{a}$ is quite simple. The long-range transport of radioactivity from Chernobyl was associated mainly with particles in the submicron range for which in-cloud scavenging processes are much more important than below cloud scavenging, see Warneck (1988). The relative humidity, is found from

$$
R H \equiv \frac{w}{w_{s}}
$$

where the mixing ratio, $w$, is calculated from the specific humidity $Q$

$w=\frac{Q}{1-Q}$

and $w_{s}$ is the saturation mixing ratio calculated from (Wallace and Hobbs, 1977)

$w_{s}=0.622 \frac{e_{s}}{p-e_{s}}$

where $p$ is the pressure and $e_{s}$ is the saturated partial pressure of water vapour, which is calculated as an approximated function of temperature, $T$ (Seinfeld, 1986)

$$
e_{s}=p_{0} \exp \left(13.3185 a-1.9760 a^{2}-0.6445 a^{3}-0.1299 a^{4}\right)(27)
$$

where $p_{0}$ is the standard pressure $(101325 \mathrm{~Pa})$ and $a$ is given by

$a=1-\frac{T_{0}}{T}$

where $T_{0}=273.15 \mathrm{~K}$. Equation (27) is valid to $\pm 0.1 \%$ in the temperature range from $50^{\circ} \mathrm{C}$ to $140^{\circ} \mathrm{C}$ (Seinfeld, 1986).

\section{Model results and comparisons to measurements}

The model system has been run with a combination of the different parameterizations for dry and wet deposition described in the previous section. The model results have been validated against measurements. Some examples of model results for Chernobyl are given in Sect. 5.1. Comparisons of the model results obtained using the different parameterizations and using different statistics, are described in Sect. 5.2.

\subsection{Model simulations of the Chernobyl accident}

Model simulations of the Chernobyl accident are different from model simulations of the two ETEX releases in 1994. The main reason for this is that Chernobyl is a real accident.
This means that several issues are connected with greater uncertainties in the case of the Chernobyl accident than is the case of the ETEX releases. This includes uncertainties in the estimation of the source term, uncertainties in the dryand wet deposition, and greater inhomogeneity in the measurements available after the accident. Greater uncertainties can therefore be expected in the model results from the Chernobyl case compared to the ETEX cases (Brandt et al., 1998a).

Measurements of surface concentrations and total depositions from three radioactive species, ${ }^{137} \mathrm{Cs},{ }^{134} \mathrm{Cs}$, and ${ }^{131} \mathrm{I}$ were available after the accident. Therefore model simulations and validation against measurements of the concentrations and depositions of these three species have been performed here. The treatment of the two caesium isotopes are similar in the model. The iodine isotope is treated differently from the caesium isotopes, partly because it has a much shorter radioactive half-life, and partly because it was released in gaseous form, where the caesium isotopes were released as particles. This influences the treatment of dry deposition in the model. Deposition of the radioactive material is an important factor when simulating accidental releases from nuclear power plants. Wet deposition can be a major removal process and a large source for radioactive contamination. The different parameterizations of dry- and wet deposition have been compared and tested against measurements of total accumulated deposition for all three species.

The parameterizations of mixing height and dispersion have been chosen from the results of the experiments performed for the ETEX releases (Brandt et al., 1998a). In our simulations of the Chernobyl accident, the mixing height is parameterized based on a bulk Richardson/ZilitinkevichMironov scheme, and dispersion in both the Lagrangian model and the Eulerian model is parameterized based on Monin-Obukhov similarity theory, see Brandt et al., (1998a). The meteorological data used for the Chernobyl episode are analyzed data obtained from ECMWF with a $1.5^{\circ} \times 1.5^{\circ}$ horizontal resolution. The experiments with ETEX, demonstrated that using the MM5V1 as a meteorological driver improve the results in general compared to the case where the analyzed data are used. Therefore data obtained from running MM5V1, using ECMWF $\left(1.5^{\circ} \times 1.5^{\circ}\right)$ analysis data with the truncation T106 as input to MM5V1, have been used as meteorological input data to DREAM in the simulations presented here. Time resolution of input data is $6 \mathrm{~h}$ on 14 standard pressure levels. Assimilation of input data is performed with four dimensional data assimilation (FDDA). The model is run with a forcing term that nudges it towards the next analysis remaining close to a dynamical balance. Furthermore the analysis is initialized after spatial interpolation by using non-linear normal mode initialization. The boundary conditions were updated with the ECMWF data every 6 hours. Both simple and comprehensive parameterizations are available for parameterization of the planetary boundary layer, moisture schemes, cumulus parameter- 
${ }^{137}$ Cs concentrations, Chernobyl, MM5V1

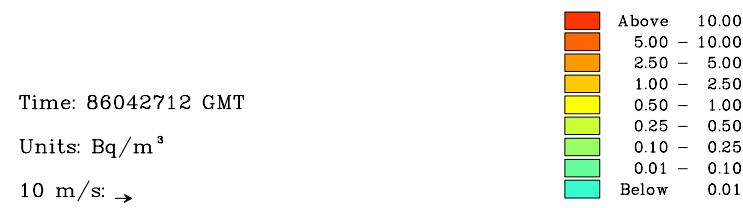

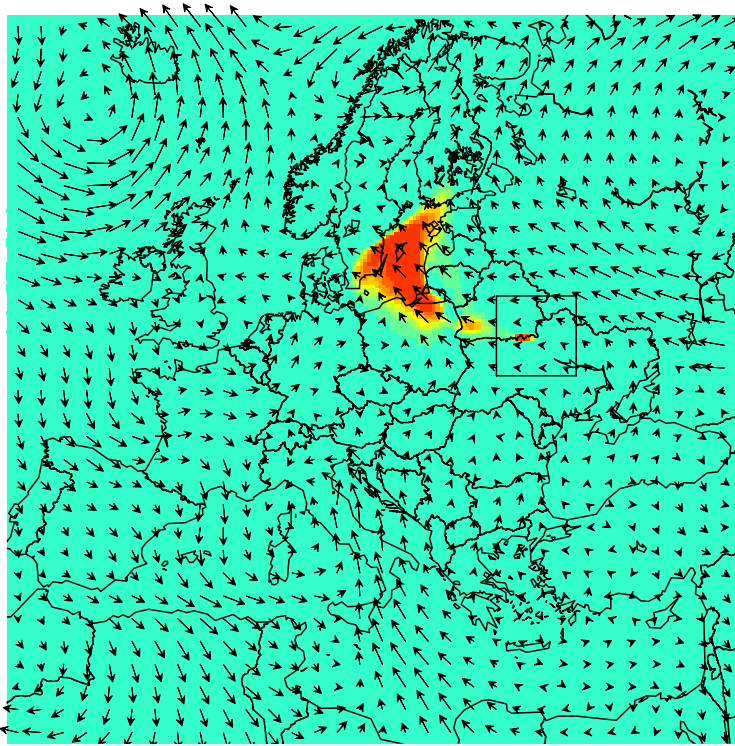

Cs concentrations, Chernobyl, MM5V1

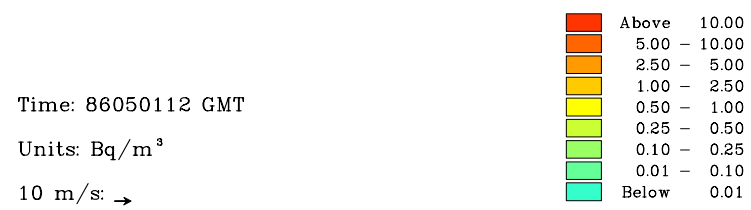

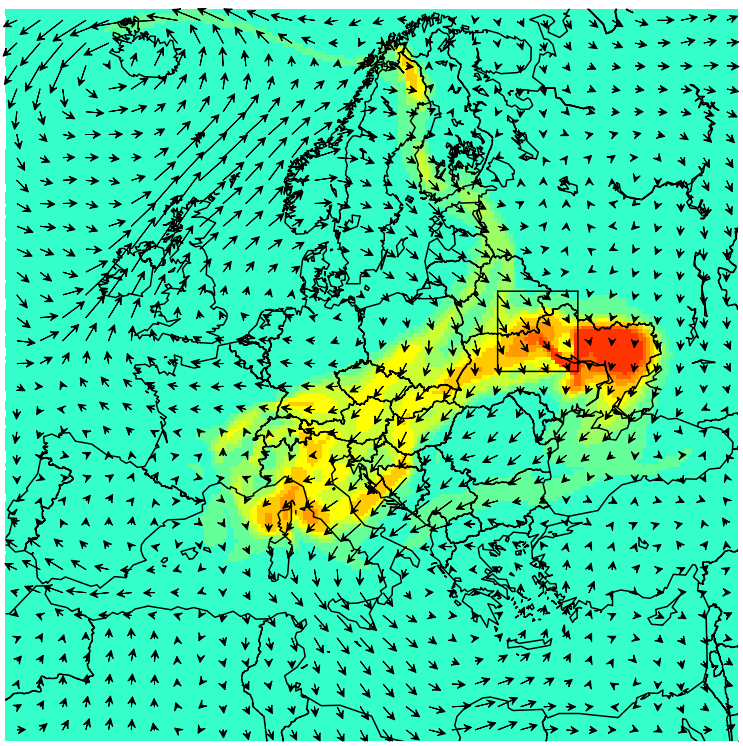

$1{ }^{7} \mathrm{Cs}$ concentrations, Chernobyl, MM5V1

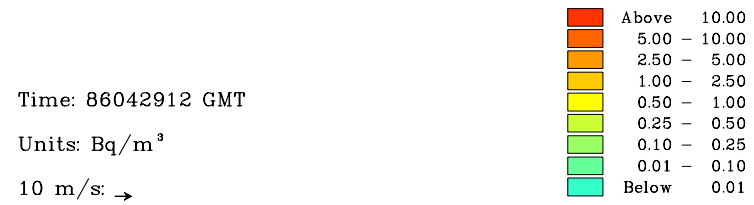

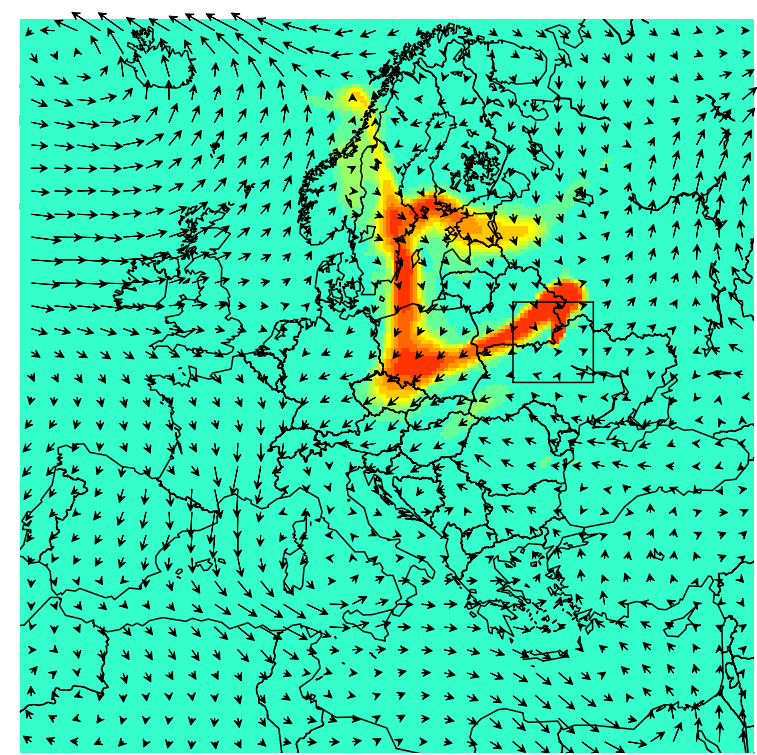

Cs concentrations, Chernobyl, MM5V1
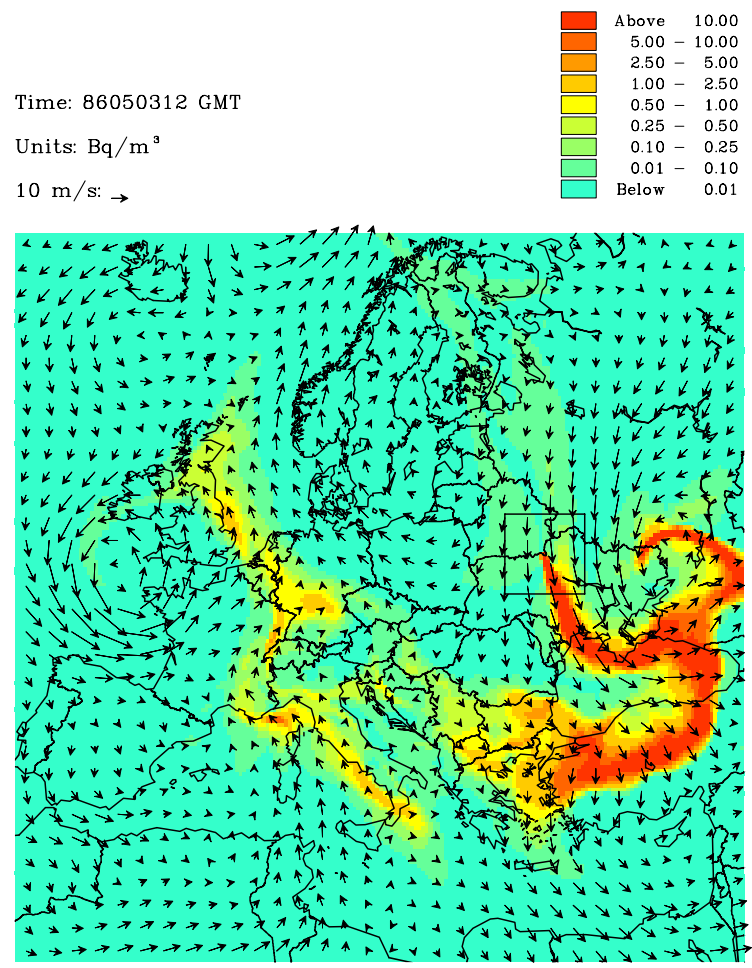

Fig. 1. Model simulation of the development of the surface concentrations of ${ }^{137} \mathrm{Cs}$ from the Chernobyl accident. The figures show the situation with two days interval, starting at 27 April, 12:00 UTC (the day after start of release) and ending 12 days after start of release. Dry deposition is based on the simple dry deposition scheme and wet deposition is parameterized based on subgrid-scale averaging. 
${ }^{137}$ Cs concentrations, Chernobyl, MM5V1

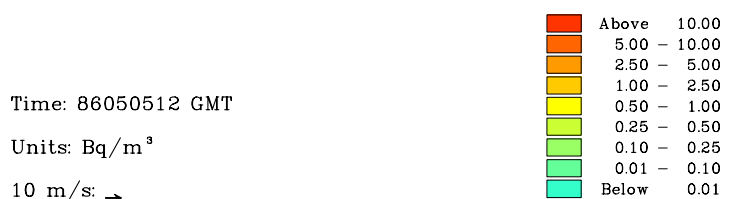

$10 \mathrm{~m} / \mathrm{s}:$

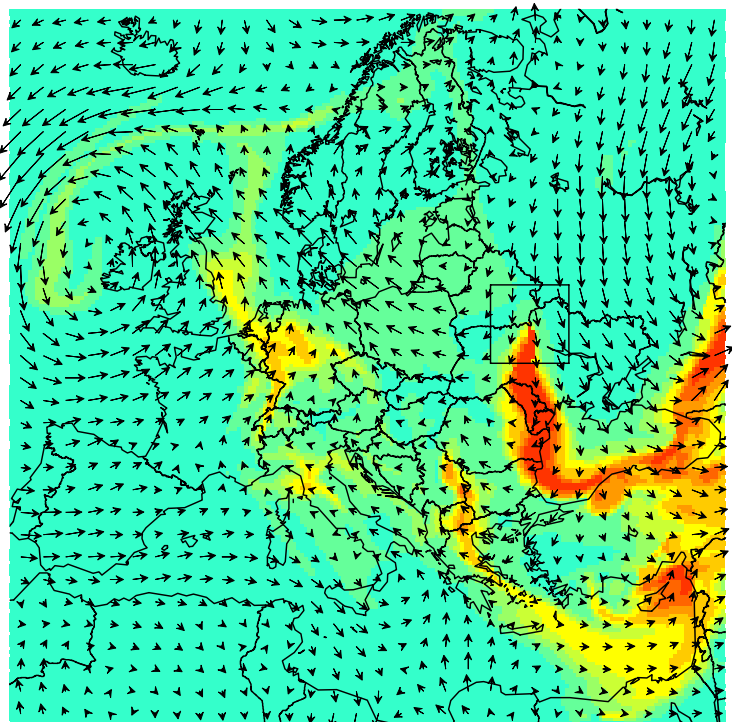

${ }^{13}$ Cs concentrations, Chernobyl, MM5V1

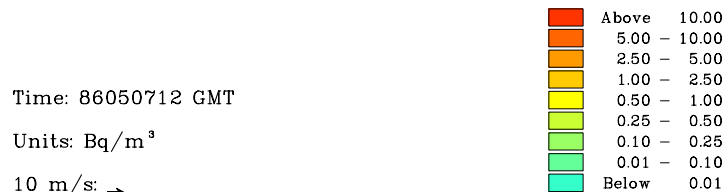

$10 \mathrm{~m} / \mathrm{s}:$,

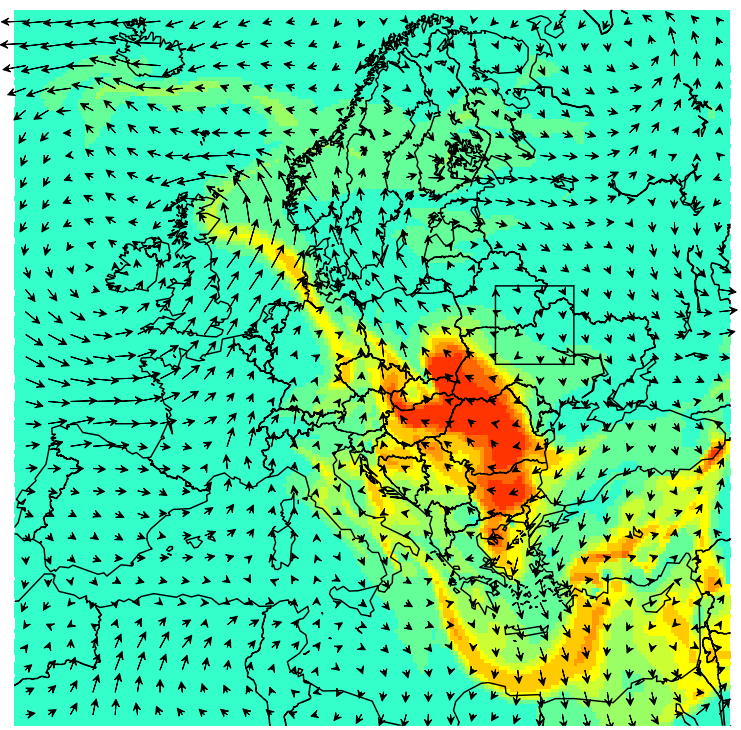

Fig. 1. Continued ...

ization and atmospheric radiation schemes (see Chen et al., 1995). The different schemes chosen in these model simulations, are the most comprehensive schemes, which should give the most accurate results. The high-resolution multilayer Blackadar planetary boundary layer formulation is applied. A complex explicit moisture scheme is used, including a mixed phase scheme with five prognostic variables (specific humidity, cloudwater, rainwater, cloud ice and snow). In addition the Arakawa-Schubert cumulus parameterization, which is a multi-cloud scheme suitable for larger scales and allowing for entrainment into updrafts and downdrafts, is applied. An atmospheric cloud-radiation scheme, which is applied in all layers, accounts for longwave and shortwave interactions with cloud and vapor and predicts the surface temperature.

An example of the development of the surface concentrations of ${ }^{137} \mathrm{Cs}$ from the Chernobyl accident, calculated by using DREAM, is illustrated in Fig. 1. The figure shows the situation at two day intervals, starting at 27 April, 12:00 UTC and ending at 7 May, 12:00 UTC. The initial transport of the radioactive species was towards northwest to Sweden and Finland. It is seen in the upper left plot in Fig. 1 that the surface concentrations were close to zero near the accident site in the initial phase. This is due to the source term used in the model. The effective release heights from the Chernobyl accident have been estimated to have different values during the accident (see Sect. 3). The major part of the initial emissions from Chernobyl has been estimated to take place at relatively high altitudes. After a few days the major parts of the emissions took place at lower altitudes. In the following days the concentrations were transported over most of Europe with major exposures in southern, eastern and central Europe.

A three dimensional illustration of the $0.15 \mathrm{~Bq} \mathrm{~m}^{-3}$ isosurface on the third day after the accident on 28 April, 12:00 UTC, is shown in Fig. 2. The figure shows the situation seen from the south. The surface concentrations are plotted on the iso-surface. The blue areas on the iso-surface indicate the parts of the plume, which do not have direct contact with the ground. A great part of the wet deposition came from these parts of the plume, which can be seen when comparing the surface concentrations (Fig. 1) with the total depositions (Fig. 7). This is especially true for Finland. It is also seen in the figures, that some parts of the plume are transported by the vertical wind to higher altitudes where the wind direction is opposite the direction at lower levels. This results in transport of the plume in opposite directions at different altitudes, both towards northwest at lower altitudes and towards southeast at higher altitudes.

Some examples of comparisons with measurements are illustrated as scatter plots in Fig. 3. The locations of the measurement stations where measurements of deposition were 


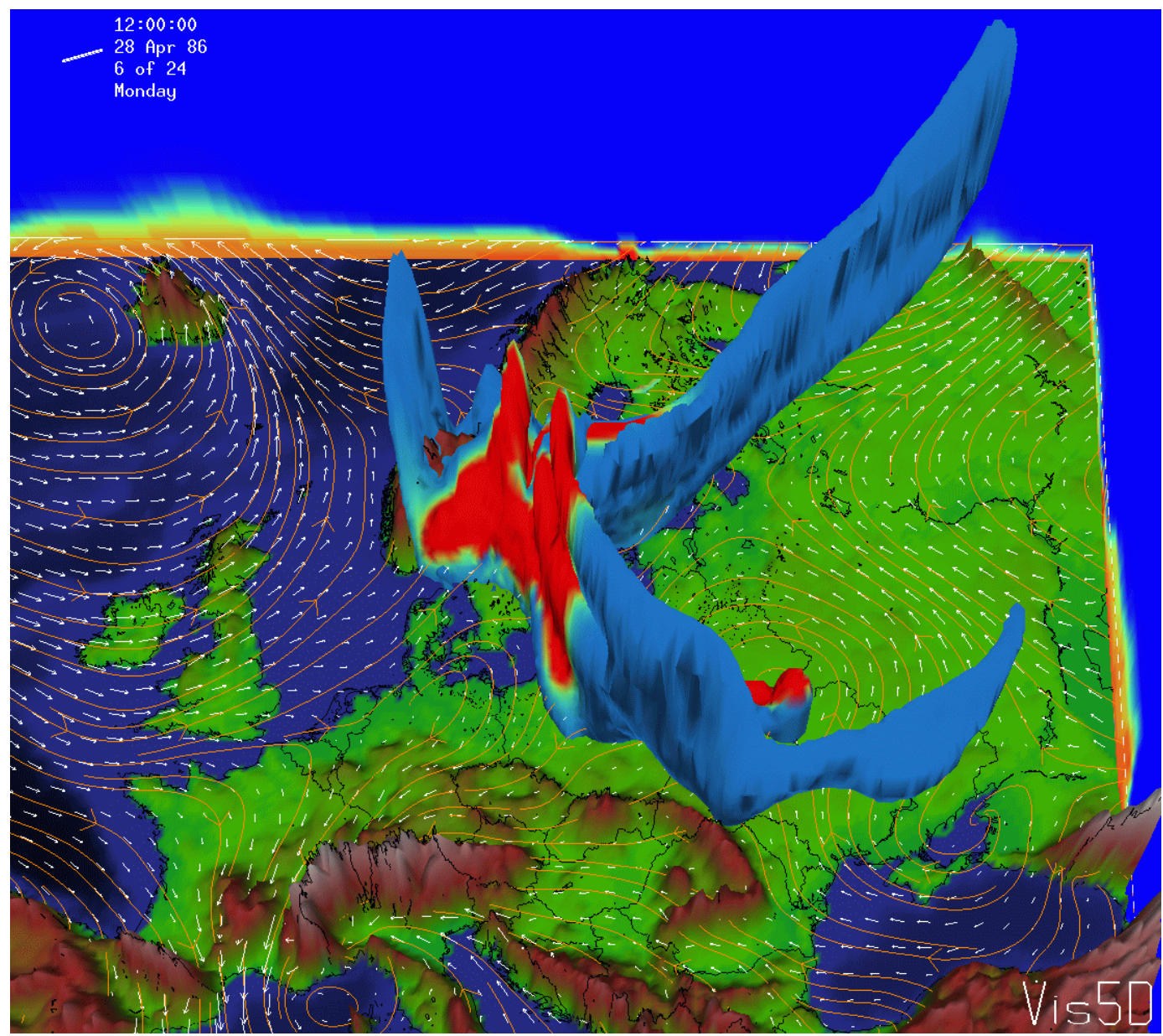

Fig. 2. Fig. 2. A three-dimensional illustration of the $0.15 \mathrm{~Bq} \mathrm{~m}^{-3}$ iso-surface of ${ }^{137} \mathrm{Cs}$ from the Chernobyl accident, on the third day after the accident, 28 April, 12:00 UTC. Parameterizations are the same as in Fig. 1. The surface concentrations are plotted on the iso-surface and are the same as given in Fig. 1 (red indicate high surface concentrations and blue indicate low surface concentrations). The blue color on the plume therefore indicates parts of the plume, which does not have contact with the ground. The bulk Richardson number is given as vertical slices at the boundaries. The blue color at the boundaries indicate the domain where the bulk Richardson number exceeds the critical value of 0.25 , and is therefore an indicator of the height of the planetary boundary layer.

carried out are given in Fig. 4. The measurements have been obtained from the REM-database at the Environment Institute, Joint Research Center, Ispra, Italy. The figure shows scatter plots of the total dosages, the arrival time, the duration, and the total depositions for the specie ${ }^{137} \mathrm{Cs}$. Taking into account the uncertainties in the source term, the inhomogeneities in the measurements and the uncertainties in the depositions, the model gives quite good results for the Chernobyl case. There is a relatively large bias in the dosages, which can be explained from biases in the source term or uncertainties in the effective release heights. This bias could easily be adjusted by changing the emission rates, but this correction in the emissions has not been performed, due to the other uncertainties, especially in the wet deposition. However, the correlation coefficient for the dosages is highly significant. The model is able to predict the arrival times to the measurement stations quite accurately with a correlation coefficient of 0.86 . The model is also able to reproduce the duration's (meaning the time between the arrival time and the time where the plume leaves a specific location) within a factor of two, which is comparable to the ETEX cases (Brandt et al., 1998a). The comparisons of model calculations of the total depositions with measurements show that the model is able to estimate the general level of the total deposition and with a significant correlation coefficient.

Below each figure (in Fig. 3), some global statistics are shown. Some of these are used for the comparison of the model results, obtained by using the different parameterizations (see next subsection). The statistics include the number of points, $N$, the mean values, the standard deviations, the correlation coefficient with a test statistic, the figure of merit, $F M$, the bias with the $95 \%$ confidence inter- 
DOSAGES, CHERNOBYL, ${ }^{137} \mathrm{Cs}$

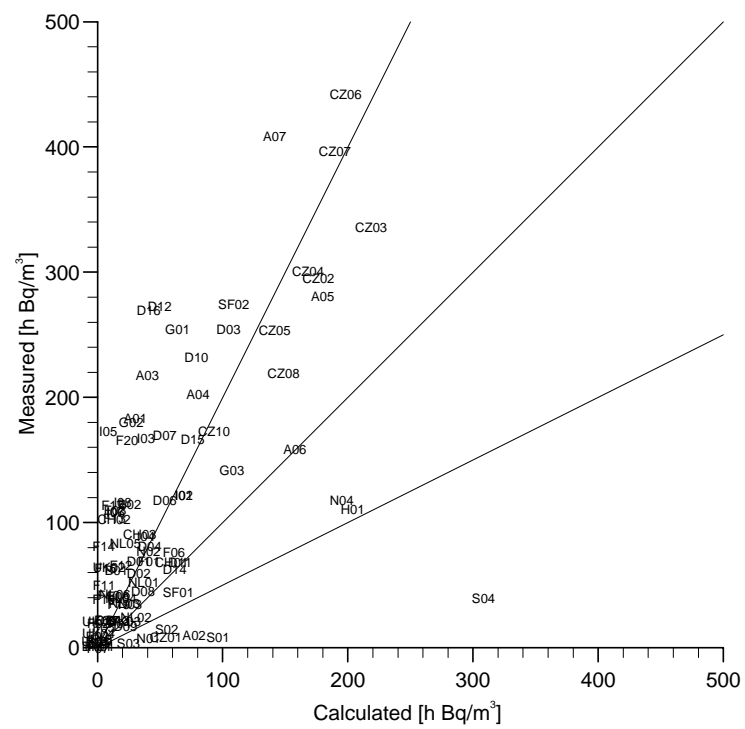

No. of points $=97$, means: calculated $=55.69$, measured $=116.80$ Standard deviations: calculated $=61.83$, measured $=122.52$ correlation $=0.61$, test statistic $(\mathrm{H}$ : corr $=0)=7.51, F M=38.00 \%$ bias $=-61.110, \mathrm{ci}_{\text {bas }}(95 \%)=+/-19.532, \mathrm{FB}=-0.709, \mathrm{FSD}=-1.188$ NMSE $=2.040, \operatorname{ci}_{\text {NMSE }}(95 \%)=+/-0.456$
ARRIVAL TIME, CHERNOBYL, ${ }^{137} \mathrm{Cs}$

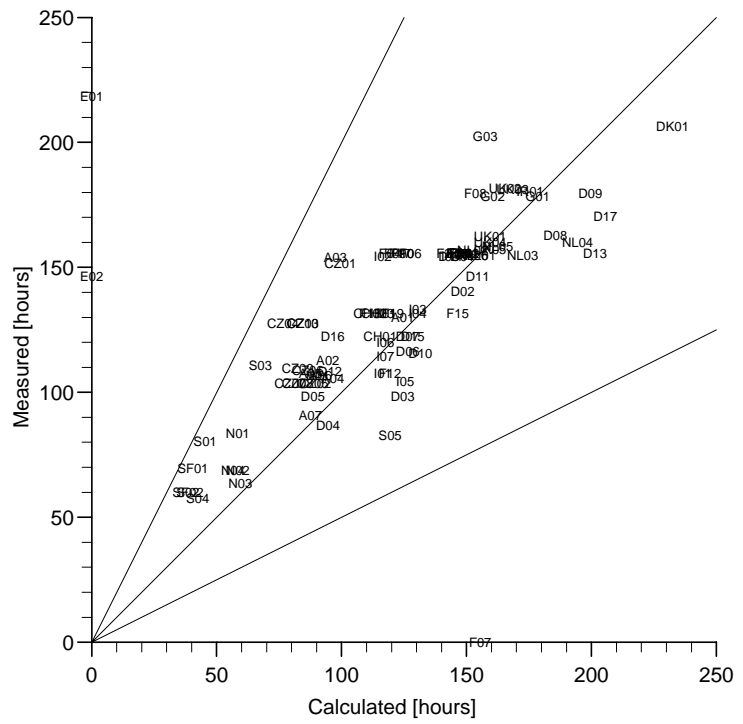

No. of points $=97$, means: calculated $=120.72$, measured $=131.90$ Standard deviations: calculated $=43.47$, measured $=36.57$ correlation $=0.87$, test statistic $(\mathrm{H}$ : corr $=0)=17.00, F M=87.00 \%$ bias $=-11.185, \mathrm{Ci}_{\text {bias }}(95 \%)=+/-7.245, \mathrm{FB}=-0.089, \mathrm{FSD}=0.342$ NMSE $=0.030, \mathrm{Ci}_{\text {NMSE }}(95 \%)=+/-0.004$

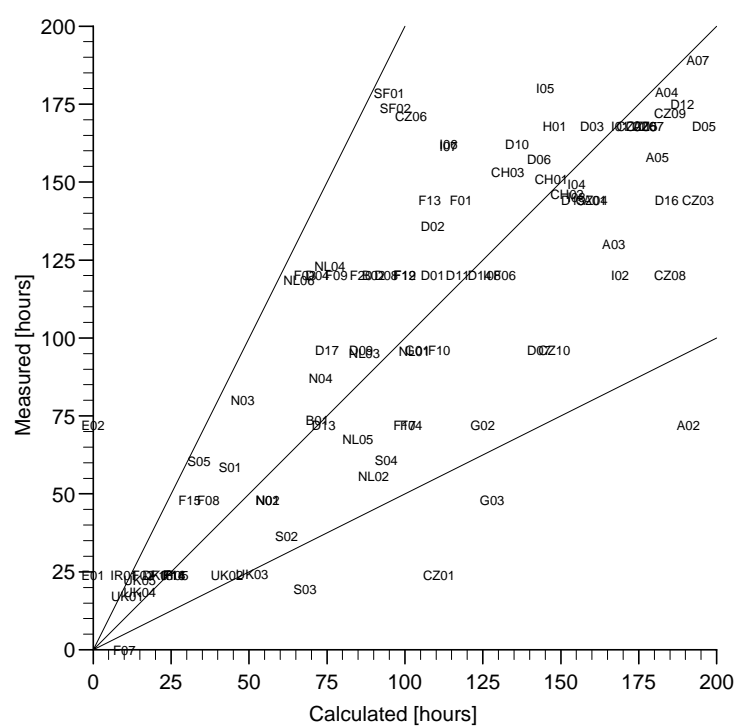

No. of points $=97$, means: calculated $=103.13$, measured $=103.18$ Standard deviations: calculated $=55.22$, measured $=53.11$ correlation $=0.80$, test statistic $(\mathrm{H}$ : corr $=0)=12.80, \mathrm{FM}=79.00 \%$ bias $=-0.042, \mathrm{Ci}_{\text {bias }}(95 \%)=+-\quad 6.812, \mathrm{FB}=0.000, \mathrm{FSD}=0.078$ NMSE $=0.103, \mathrm{Ci}_{\text {NMSE }}(95 \%)=+/-0.030$
TOTAL DEPOSITION, CHERNOBYL, ${ }^{137} \mathrm{Cs}$

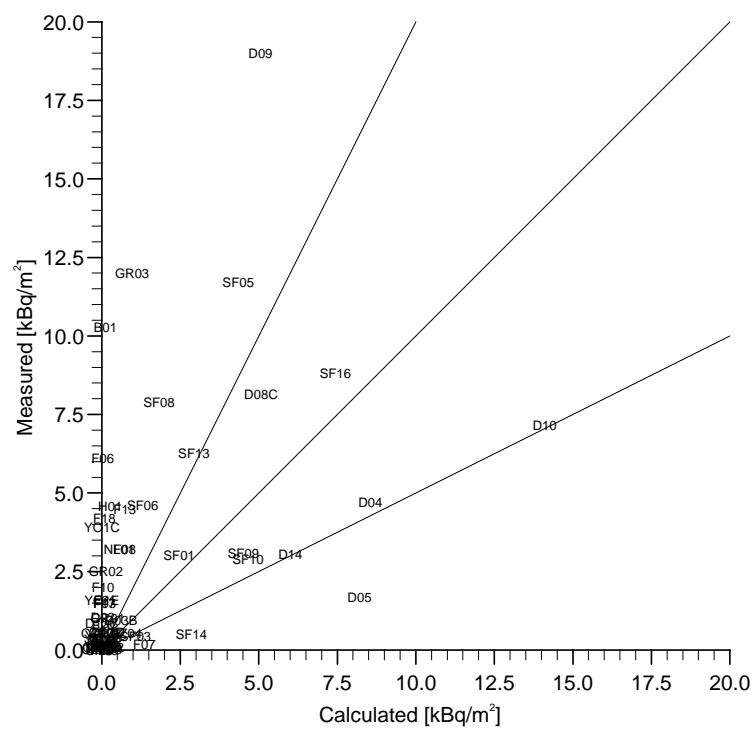

No. of points $=67$, means: calculated $=1.32$, measured $=2.49$ Standard deviations: calculated $=2.62$, measured $=3.60$ correlation $=0.47$, test statistic $(\mathrm{H}:$ corr $=0)=4.35, \mathrm{FM}=31.00 \%$ bias $=-1.168, \mathrm{Ci}_{\text {bias }}(95 \%)=+/-0.789, \mathrm{FB}=-0.612, \mathrm{FSD}=-0.616$ NMSE $=3.654$, Ci $_{\text {NMSE }}(95 \%)=+/-1.230$

Fig. 3. A comparison of model calculations of ${ }^{137}$ Cs with measurements for Chernobyl at 97 measurement stations (67 stations for deposition). Parameterizations are the same as in Fig. 1. Upper left: dosages (integrated concentrations for every hour over the whole period). Upper right: arrival times - meaning the time where the plume arrives to the different measurement stations. Lower left: duration (the time between the time of arrival of the plume and the time where the plume leaves the location of the measurement stations). Lower right: total deposition at 67 stations. 


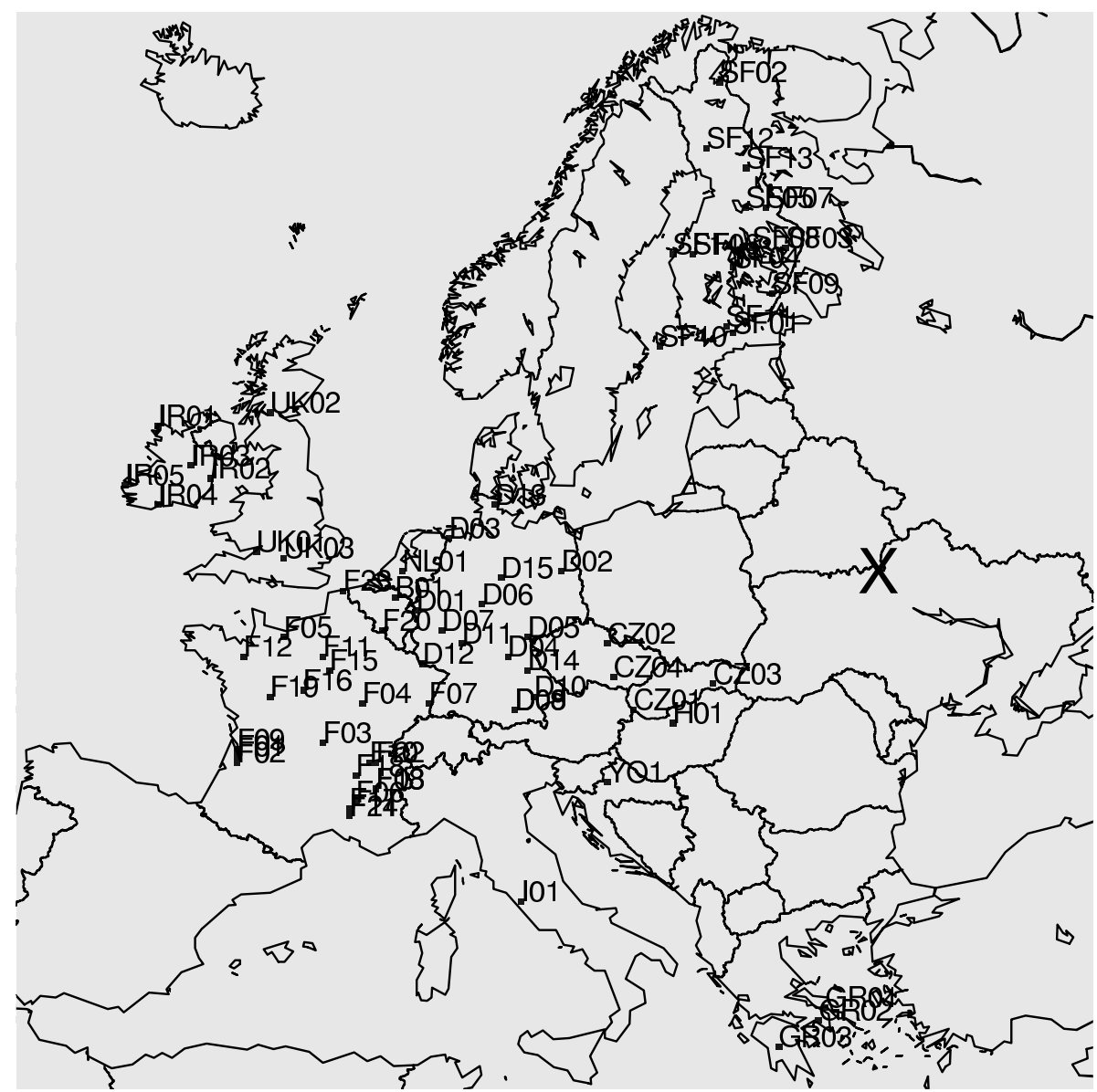

Fig. 4. Location of the measurement stations, where measurements of the total depositions are available in connection with the Chernobyl accident (from the REM database). "X" denotes the location of the release site. val, the fractional bias, $F B$, the fractional standard deviation, $F S D$ and the normalized mean square error, $N M S E$, with the $95 \%$ confidence interval. A detailed description of the various statistical parameters is given in Spiegel (1992) and Mosca et al. (1997) and also used in Brandt (1998) and Brandt et al. (1998a). A test for significance has been performed for the correlation coefficient by the test parameter $t_{c}=r(N-2)^{1 / 2}\left(l-r^{2}\right)^{-1 / 2}$ where $r$ is the correlation coefficient and $N$ is the number of data (Spiegel, 1992). The test hypothesis is that the model results and measurements are linearly independent which means that the correlation coefficient is zero. If the hypothesis can be rejected at a given significance level, the correlation coefficient is assumed to be significant at that level. Critical values for the test parameter for $N=100$ are $1.66,2.63$ and 3.39 corresponding to significance levels of $0.1(10 \%), 0.01(1 \%)$ and $0.001(0.1 \%)$, respectively (Spiegel, 1992).

5.2 Comparisons of different parameterizations of dry- and wet deposition

Accurate parameterizations of dry- and wet deposition are important for reliable model results in the Chernobyl case. In this section the parameterizations of dry- and wet depositions for the three species ${ }^{137} \mathrm{Cs},{ }^{134} \mathrm{Cs}$, and ${ }^{131} \mathrm{I}$ are compared. Figures 5 and 6 show examples of the accumulated dry- and wet depositions for ${ }^{137} \mathrm{Cs}$, using the different parameterizations. Some examples of the accumulated total depositions are given in Fig. 7. All figures illustrate the situation at the end of the simulation period, at 7 May, 12:00 UTC.

In Fig. 5 the accumulated dry deposition of ${ }^{137} \mathrm{Cs}$ is shown, using the three different parameterizations: the parameterization based on the simple dry deposition algorithm, the parameterization based on the resistance method for particles, and dry deposition based on a constant deposition velocity. As shown in Table 2 there are large differences in the magnitude of the deposition velocities of the radioactive species ${ }^{137} \mathrm{Cs}$ and ${ }^{131} \mathrm{I}$, which has been recommended and used in different models. Therefore the same constant value for the dry deposition velocity of $0.2 \mathrm{~cm} \mathrm{~s}^{-1}$ has been chosen and applied here for all three species. The three parameterizations of dry deposition give in general the same patterns but with some differences in the general levels and the levels over waters and forests. The constant value of $0.2 \mathrm{~cm} \mathrm{~s}^{-1}$ seems to give larger deposition for caesium compared to the simple dry deposition method and especially the resistance method. 

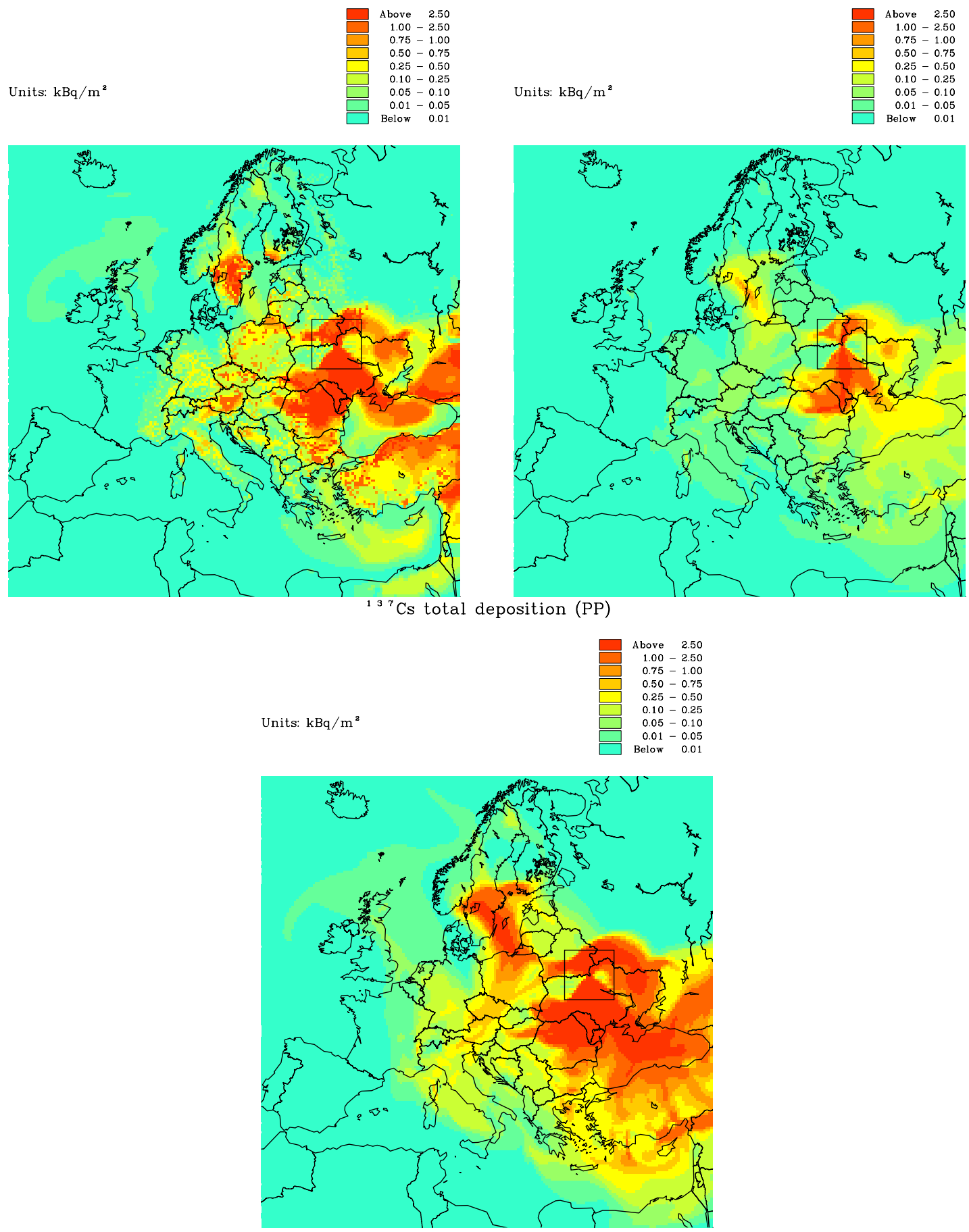

Fig. 5. Accumulated dry deposition of ${ }^{137} \mathrm{Cs}$ from the Chernobyl accident, at the end of the simulation period (7 May, 12:00 UTC), calculated using three different schemes. Upper left: simple dry deposition method. Upper right: parameterization based on the resistance method for particles. Lower figure: constant deposition velocity $\left(0.2 \mathrm{~cm} \mathrm{~s}^{-1}\right)$.

The accumulated wet deposition, using the parameterizations based on subgrid-scale averaging and precipitation rates, and examples of the total accumulated deposition are shown in Figs. 6 and 7, respectively. The examples of total accumulated depositions are given as the sum of the dry deposition based on the simple dry deposition method and the wet deposition based on the two different schemes, respectively. It is clearly seen in the figure, that wet deposition ac- 

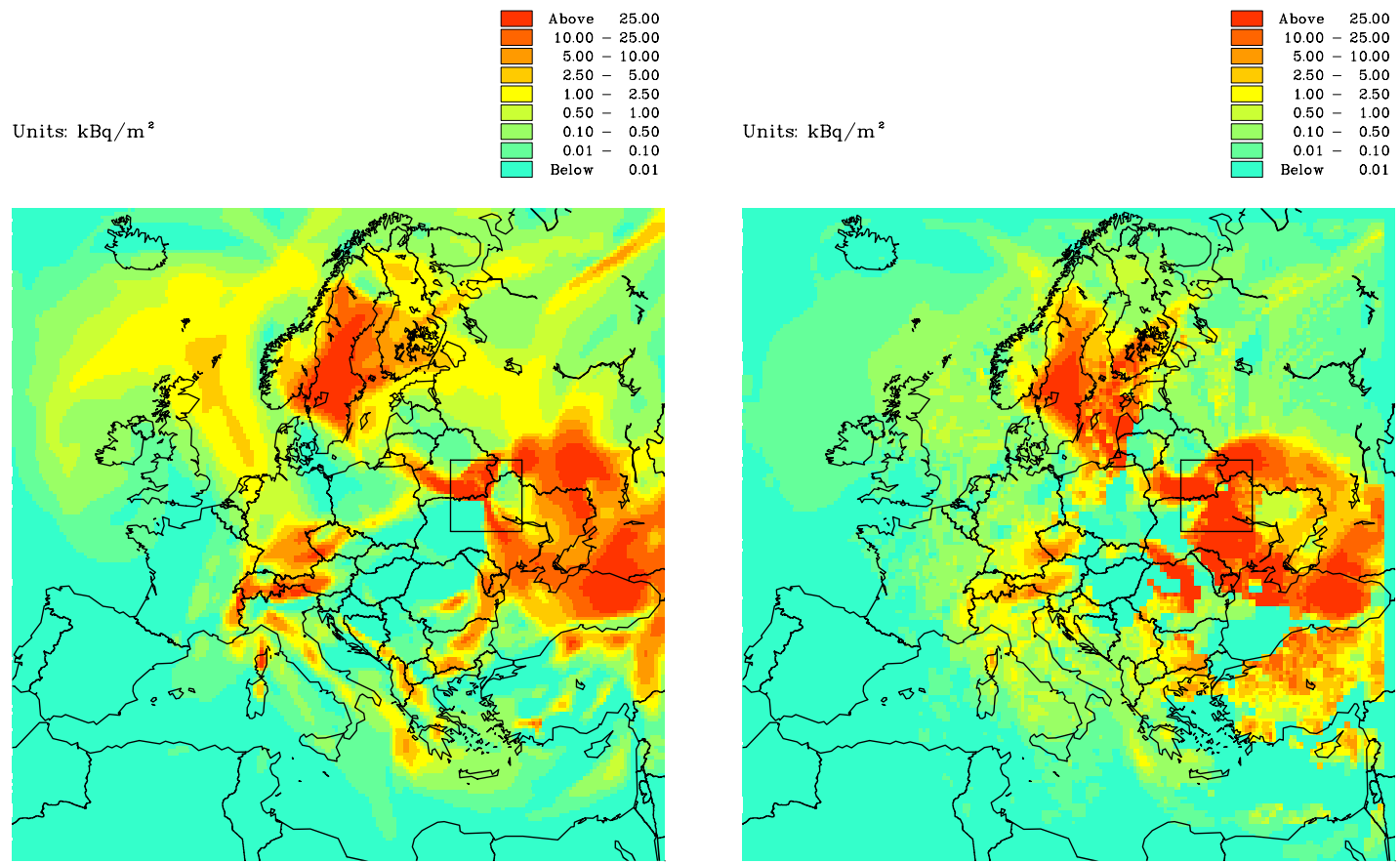

Fig. 6. Accumulated wet deposition of ${ }^{137} \mathrm{Cs}$, calculated using two different schemes from the Chernobyl accident, at the end of the simulation period (7 May, 12:00 UTC). Left: accumulated wet deposition based on subgrid-scale averaging. Right: accumulated wet deposition based on precipitation rates.

${ }^{13}{ }^{7} \mathrm{Cs}$ total deposition (PP)

${ }^{13}{ }^{7}$ Cs total deposition (PP)

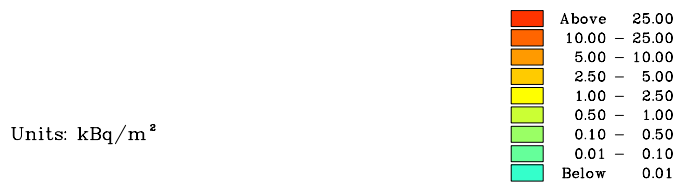

Units: $\mathrm{kBq} / \mathrm{m}^{2}$
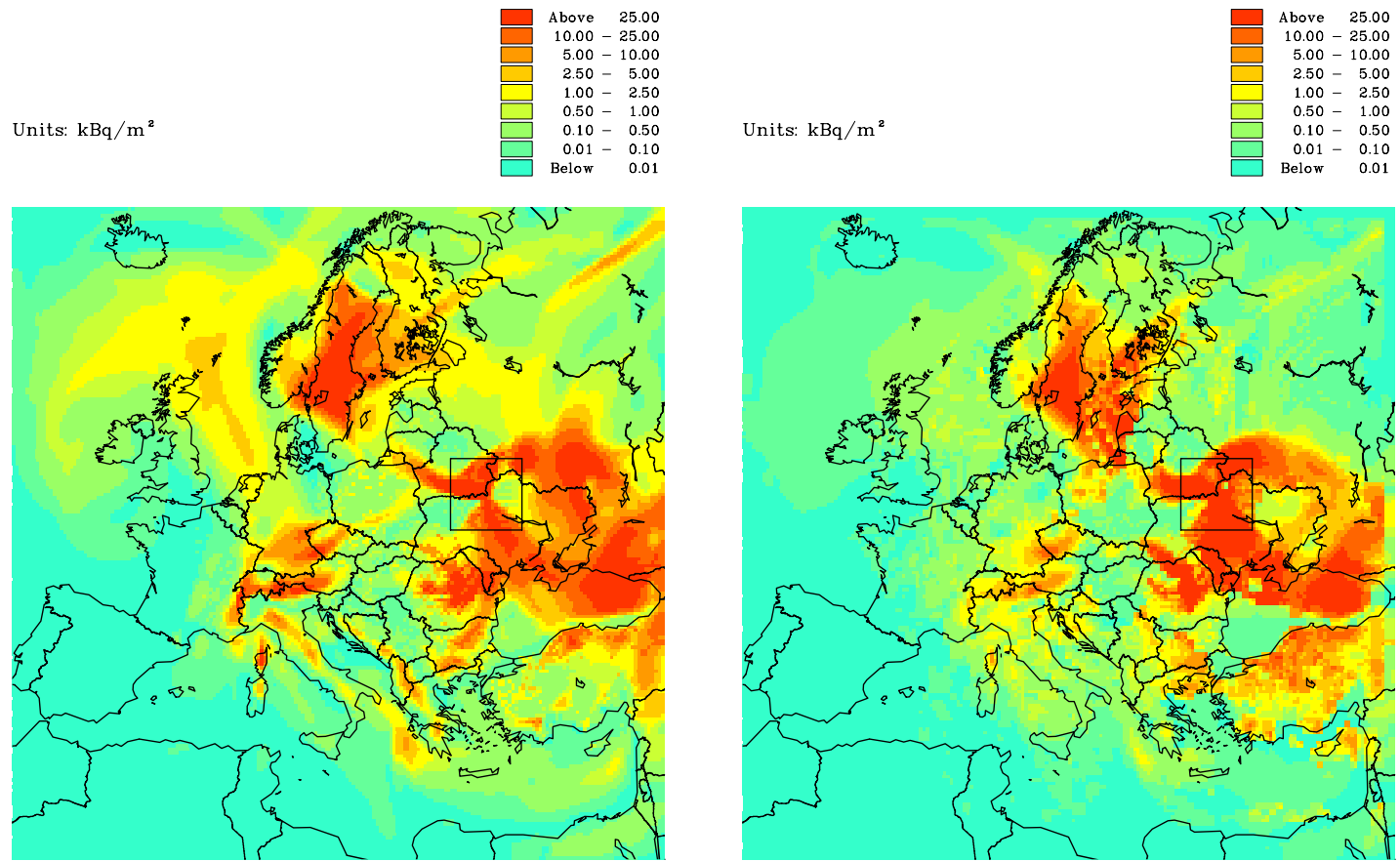

Fig. 7. Examples of the accumulated total deposition of ${ }^{137} \mathrm{Cs}$ from the Chernobyl accident at the end of the simulation period (7 May, 12:00 UTC). Left: accumulated total deposition based on subgrid-scale averaging for wet deposition and the simple method for dry deposition. Right: accumulated total deposition based on precipitation rates for wet deposition and the simple method for dry deposition. 
counts for the major part of the total deposition. Some differences are seen in the general patterns between the two parameterizations of wet deposition, especially over the Baltic sea, the North sea, the Alpine regions, and in the south-eastern Europe, as e.g. Rumania, Bulgaria and Greece.

Comparisons of combinations of the three different parameterizations of dry deposition and the two different parameterizations of wet deposition are given in Tables 4-7. In Tables 4-6 the six different combinations have been compared to measurements using the REM database of the total deposition for the three species, ${ }^{137} \mathrm{Cs},{ }^{134} \mathrm{Cs}$, and ${ }^{131} \mathrm{I}$ and statistics have been calculated. The statistics in the tables are the same as the statistics used in the scatter plots.

In order to evaluate the different model results, obtained by using different combinations of the dry and wet deposition schemes and to estimate the best performing combination, a ranking of the different model simulations has been carried out. For each model run, the correlation coefficient, the bias with $95 \%$ confidence interval, the NMSE with $95 \%$ confidence interval, the $F B$, the $F S D$ and the $F M$ have been calculated for the total deposition. The $95 \%$ confidence intervals for the bias and the NMSE are considered as separate statistics, because it is possible to obtain values for the bias or the NMSE, which indicates very good performance, but with confidence intervals, which indicate bad performance. The opposite is also possible. For each statistical parameter a local ranking has been performed, meaning that the best performing value has been given the value 1 , the second best performing value has been given the value 2, etc. Each statistical index has been given the same weight. After the local ranking of each index, a global rank is calculated as the sum of the local rank. In this way, the result with the smallest global rank indicates the best performing model in terms of model results compared to measurements. The lowest value of the global rank (indicating the best performing parameterization), that can be obtained in this case is 8 , and the highest value (indicating the worst performing parameterization) is 48.

The same major conclusion is obtained from the global ranking for the three different radioactive isotopes. The best performance, compared to measurements, is obtained by the total deposition combined of the simple dry deposition method and the wet deposition based on subgrid-scale averaging. Large differences are seen in the results obtained by using the two different parameterizations of wet deposition. The parameterization based on subgrid-scale averaging is, in all cases, performing better than the parameterization based on precipitation rates (with respect to the global ranks). This indicates that the precipitation rates are relatively uncertain in the meteorological model and that the in-cloud scavenging processes are the most important for the long range transported submicron particles compared to the below cloud scavenging processes. Relatively small differences are, however, seen in the statistical tests between the three different parameterizations of dry deposition. This is due to the fact that the major part of the total deposition consists of wet deposition.

The European Commission, Environment Institute, Joint Research Center, Ispra, Italy, has in 1998 produced an atlas based on measurements, with the title: "Atlas of caesium deposition on Europe after the Chernobyl accident". In this atlas, estimates of the total depositions for 31 countries influenced by the Chernobyl accident are given. The results are based on a large number of surface samples taken all over Europe and maps have been produced together with the estimates of deposition on each of the 31 countries. The model was setup to provide corresponding results for each of these countries, and the model results have been compared to the estimates given in the atlas. The results from the comparison are given in Table 7. The table is similar to the Tables 4-6, however, only caesium is included in this comparison. The best performance is (as the case where the REM database is used) obtained by the total deposition combined of the simple dry deposition method and the wet deposition based on subgrid-scale averaging. Highly significant and relatively larger correlation coefficients (from 0.76-0.86) are seen when testing the model results based on country values compared to the case where individual measurement stations are used (the REM database). This should be expected, since a whole country is much more representative for the model result when comparing with measurements than individual measurement stations. Furthermore, one of the results in the atlas is an estimate of the measured total deposition for all countries giving a total measured deposition of $77 \mathrm{PBq}$. Using the combination of the different dry and wet deposition parameterizations, modelled values between $75.8 \mathrm{PBq}$ and $99.18 \mathrm{PBq}$ are obtained (see Table 7). All the results obtained when the wet deposition parameterization based on subgrid-scale averaging is used gives a total deposition for all countries very close to the measured value.

\section{Conclusions}

A tracer model based on a combination of a near-range Lagrangian model and a long-range Eulerian model has been developed and validated against measurements of ${ }^{137} \mathrm{Cs}$, ${ }^{134} \mathrm{Cs}$, and ${ }^{131} \mathrm{I}$ in connection with the Chernobyl accident. Different parameterizations of dry and wet deposition in the model have been tested and compared. The conclusions are based on comparisons with measurements both from the REM database and from the Chernobyl atlas.

Simulations of the Chernobyl accident show that comprehensive tracer models are powerful tools for estimating the concentrations and depositions after a nuclear power plant accident. The validation of the DREAM model against measurements of ${ }^{137} \mathrm{Cs},{ }^{134} \mathrm{Cs}$, and ${ }^{131} \mathrm{I}$ demonstrates that the model is able to simulate the development of the specific activity fields and the accumulated total depositions with quite good results and with a high level of detail when compared 
Table 4. Comparisons of total deposition of ${ }^{137} \mathrm{Cs}$ for the Chernobyl episode based on different combinations of the wet- and dry deposition schemes. Statistics are calculated from comparisons with measurements from the REM database. Values in bold are the most significant of the 6 combinations

\begin{tabular}{lcccccc}
\hline Statistics & \multicolumn{3}{c}{ Wet deposition } & \multicolumn{3}{c}{ Wet deposition } \\
$N=67$ & \multicolumn{2}{c}{ based on relative humidity (RH) } & \multicolumn{2}{c}{ based on precipitation rates } \\
Dry deposition: & $\begin{array}{c}\text { Resistance, } \\
\text { particle }\end{array}$ & Simple & $\begin{array}{c}\text { Constant } \\
(0.2 \mathrm{~cm} / \mathrm{s})\end{array}$ & $\begin{array}{c}\text { Resistance, } \\
\text { particle }\end{array}$ & Simple & $\begin{array}{c}\text { Constant } \\
(0.2 \mathrm{~cm} / \mathrm{s})\end{array}$ \\
\hline Correlation & 0.47 & 0.47 & 0.47 & $\mathbf{0 . 5 1}$ & 0.50 & 0.49 \\
$t_{c}$ & 4.32 & 4.35 & 4.35 & $\mathbf{4 . 7 3}$ & 4.68 & 4.59 \\
\hline Bias & $\mathbf{1 . 1 6 8}$ & $\mathbf{- 1 . 1 6 8}$ & -1.205 & -1.798 & -1.810 & -1.828 \\
ci(95\%) & 0.790 & 0.789 & 0.785 & $\mathbf{0 . 7 4 8}$ & 0.750 & 0.753 \\
\hline NMSE & 3.660 & $\mathbf{3 . 6 5 4}$ & 3.755 & 7.423 & 7.609 & 7.907 \\
ci(95\%) & 1.251 & $\mathbf{1 . 2 3 0}$ & 1.279 & 6.146 & 6.421 & 6.890 \\
\hline FB & $-\mathbf{0 . 6 1 2}$ & $\mathbf{- 0 . 6 1 2}$ & -0.638 & -1.129 & -1.141 & -1.158 \\
FSD & -0.625 & $\mathbf{- 0 . 6 1 6}$ & 0.661 & -1.199 & -1.208 & -1.221 \\
\hline FM & $31.0 \%$ & $31.1 \%$ & $\mathbf{3 1 . 2 \%}$ & $25.3 \%$ & $25.0 \%$ & $24.5 \%$ \\
\hline Global ranks & 23 & $\mathbf{1 6}$ & 24 & 26 & 34 & 42 \\
\hline
\end{tabular}

Table 5. Comparisons of total deposition of ${ }^{134} \mathrm{Cs}$ for the Chernobyl episode based on different combinations of the wet- and dry deposition schemes. Statistics are calculated from comparisons with measurements from the REM database. Values in bold are the most significant of the 6 combinations

\begin{tabular}{lcccccc}
\hline $\begin{array}{l}\text { Statistics } \\
N=58\end{array}$ & \multicolumn{3}{c}{ Wet deposition } & \multicolumn{3}{c}{ Wet deposition } \\
Dry deposition: & $\begin{array}{c}\text { Resistance, } \\
\text { particle }\end{array}$ & Simple & $\begin{array}{c}\text { Constant } \\
(0.2 \mathrm{~cm} / \mathrm{s})\end{array}$ & $\begin{array}{c}\text { Resistance, } \\
\text { particle }\end{array}$ & Simple & $\begin{array}{c}\text { Constant } \\
(0.2 \mathrm{~cm} / \mathrm{s})\end{array}$ \\
\hline Correlation & 0.45 & 0.46 & 0.46 & $\mathbf{0 . 5 7}$ & 0.56 & 0.55 \\
$t_{c}$ & 3.77 & 3.83 & 3.83 & $\mathbf{5 . 1 3}$ & 5.08 & 4.97 \\
\hline Bias & $\mathbf{- 0 . 3 5 5}$ & -0.357 & -0.386 & -0.785 & -0.793 & -0.807 \\
ci(95\%) & 0.485 & 0.483 & 0.478 & $\mathbf{0 . 4 1 0}$ & 0.411 & 0.414 \\
\hline NMSE & 3.174 & $\mathbf{3 . 1 6 4}$ & 3.223 & 5.213 & 5.351 & 5.610 \\
ci(95\%) & $\mathbf{1 . 0 9 6}$ & 1.119 & 1.123 & 4.708 & 4.978 & 5.401 \\
\hline FB & $\mathbf{- 0 . 3 2 9}$ & -0.330 & -0.362 & -0.906 & -0.919 & -0.943 \\
FSD & -0.268 & $-\mathbf{0 . 2 5 9}$ & -0.315 & -0.860 & -0.870 & -0.889 \\
\hline FM & 31.3 & 31.6 & $\mathbf{3 1 . 9}$ & $30.6 \%$ & $30.4 \%$ & $29.9 \%$ \\
\hline Global ranks & 22 & $\mathbf{1 9}$ & 24 & 26 & 34 & 42 \\
\hline
\end{tabular}


Table 6. Comparisons of total deposition of ${ }^{131}$ I for the Chernobyl episode based on different combinations of the wet- and dry deposition schemes. Statistics are calculated from comparisons with measurements from the REM database. Values in bold are the most significant of the 6 combinations

\begin{tabular}{lcccccc}
\hline $\begin{array}{l}\text { Statistics } \\
N=25\end{array}$ & \multicolumn{3}{c}{ Wet deposition } & \multicolumn{3}{c}{ Wet deposition } \\
Dry deposition: & $\begin{array}{c}\text { Resistance, } \\
\text { particle }\end{array}$ & Simple & $\begin{array}{c}\text { Constant } \\
(0.2 \mathrm{~cm} / \mathrm{s})\end{array}$ & $\begin{array}{c}\text { Resistance, } \\
\text { particle }\end{array}$ & Simple & $\begin{array}{c}\text { Constant } \\
(0.2 \mathrm{~cm} / \mathrm{s})\end{array}$ \\
\hline Correlation & 0.55 & $\mathbf{0 . 6 0}$ & 0.57 & 0.31 & 0.33 & 0.31 \\
$t_{c}$ & 3.14 & $\mathbf{3 . 6 0}$ & 3.34 & 1.59 & 1.69 & 1.54 \\
\hline Bias & -2.231 & $\mathbf{- 1 . 3 1 7}$ & -1.807 & -6.034 & -5.938 & -5.987 \\
ci(95\%) & 4.205 & 4.054 & 4.218 & 3.822 & $\mathbf{3 . 7 9 0}$ & 3.850 \\
\hline NMSE & 2.392 & $\mathbf{1 . 7 8 8}$ & 2.126 & 7.625 & 7.125 & 7.497 \\
ci(95\%) & 9.853 & $\mathbf{2 . 8 4 7}$ & 4.148 & 33.284 & 29.072 & 31.603 \\
\hline FB & -0.321 & $\mathbf{- 0 . 1 7 8}$ & -0.252 & -1.196 & -1.166 & -1.181 \\
FSD & 0.336 & 0.370 & 0.389 & -1.346 & -1.332 & -1.294 \\
\hline FM & $35.3 \%$ & $\mathbf{4 4 . 8 \%}$ & $41.1 \%$ & $19.3 \%$ & $20.7 \%$ & $19.4 \%$ \\
\hline Global ranks & 24 & $\mathbf{1 2}$ & 21 & 43 & 30 & 38 \\
\hline
\end{tabular}

Table 7. Comparisons of total deposition of ${ }^{137} \mathrm{Cs}$ for the Chernobyl episode based on different combinations of the wet- and dry deposition schemes. Statistics are calculated from comparisons with measurements from the Chernobyl atlas (country based). Values in bold are the most significant of the 6 combinations. Total measured deposition is $77 \mathrm{PBq}$ (De Cort et al., 1998)

\begin{tabular}{|c|c|c|c|c|c|c|}
\hline \multirow{2}{*}{$\begin{array}{l}\text { Statistics } \\
N=31 \\
\text { Dry deposition: }\end{array}$} & \multicolumn{3}{|c|}{$\begin{array}{c}\text { Wet deposition } \\
\text { based on relative humidity }(\mathrm{RH})\end{array}$} & \multicolumn{3}{|c|}{$\begin{array}{c}\text { Wet deposition } \\
\text { based on precipitation rates }\end{array}$} \\
\hline & $\begin{array}{l}\text { Resistance, } \\
\text { particle }\end{array}$ & Simple & $\begin{array}{l}\text { Constant } \\
(0.2 \mathrm{~cm} / \mathrm{s})\end{array}$ & $\begin{array}{l}\text { Resistance, } \\
\text { particle }\end{array}$ & Simple & $\begin{array}{l}\text { Constant } \\
(0.2 \mathrm{~cm} / \mathrm{s})\end{array}$ \\
\hline Correlation & 0.84 & 0.85 & 0.86 & 0.79 & 0.77 & 0.76 \\
\hline$t_{c}$ & 8.22 & 8.68 & 8.95 & 7.01 & 6.44 & 6.39 \\
\hline Bias & -0.178 & -0.024 & -0.183 & 0.563 & 0.589 & 0.516 \\
\hline $\operatorname{ci}(95 \%)$ & 0.919 & 0.865 & 0.832 & 1.292 & 1.392 & 1.389 \\
\hline NMSE & 1.737 & 1.416 & 1.429 & 2.503 & 2.875 & 2.930 \\
\hline $\operatorname{ci}(95 \%)$ & 7.966 & 8.093 & 8.250 & 2.946 & 2.993 & 3.026 \\
\hline FB & -0.091 & -0.012 & -0.094 & 0.242 & 0.252 & 0.224 \\
\hline FSD & -0.005 & -0.086 & -0.215 & 0.535 & 0.579 & 0.567 \\
\hline FM & $54.9 \%$ & $58.5 \%$ & $60.2 \%$ & $49.2 \%$ & $46.9 \%$ & $47.0 \%$ \\
\hline Global ranks & 19 & 16 & 20 & 33 & 40 & 38 \\
\hline Total deposition & 76.7 PBq & $80.4 \mathrm{PBq}$ & 75.8 PBq & $99.13 \mathrm{PBq}$ & $99.18 \mathrm{PBq}$ & 97.07 PBq \\
\hline
\end{tabular}


to the maps in the Chernobyl atlas (not shown here). The accuracy of the simulations of the dosages compared to measurements is within a factor of two to three in the worst cases, which is the same accuracy as in the case of ETEX-1 (Brandt et al., 1998a). This is very good, taking into account the uncertainties in the source term, the deposition processes and the inhomogeneities in the measurements. The comparisons of model simulations with measurements of the arrival times and the durations illustrate, that the model is able to simulate these variables with an accuracy within a factor of less than two. The model simulations of the total depositions show that the model is able to reproduce the general levels of the deposition when the results are compared to measurements.

Comparisons of the different parameterizations of dry and wet deposition showed that the combination of the relatively simple dry deposition scheme and the wet deposition scheme based on subgrid-scale averaging gave the best performance. This was seen for all three species $\left({ }^{137} \mathrm{Cs},{ }^{134} \mathrm{Cs}\right.$, and $\left.{ }^{131} \mathrm{I}\right)$ and for both databases (the REM database from Ispra and the country-based estimations of ${ }^{137} \mathrm{Cs}$ deposition from the Chernobyl Atlas). This emphasizes the validity of the results.

The long range transport of radioactivity from Chernobyl was associated mainly with particles in the submicron range for which in-cloud scavenging processes are much more important than below cloud scavenging. This can explain why the subgrid-scale averaging scheme is performing better than the scheme based on precipitation rates. However, the scheme based on precipitation rates should also be able to describe this process since the in-cloud scavenging process is also included in this scheme. In both schemes a scavenging coefficient is calculated either by using the relative humidity fields or by using the precipitation fields from the MM5 model. The performance of the two schemes depend on how accurately the relative humidity or the precipitation is described in the MM5 model and on the accuracy of the parameterization of the scavenging coefficients in the two schemes. Given the better performance of the subgrid-scale averaging scheme, this confirms that the in-cloud scavenging process is more important for the radioactive submicron particles than the below cloud scavenging - probably due to in-cloud condensation processes. One important issue could also be the hydroscopic characteristics of the radioactive particles. The authors have not been able to find anything about this in the literature for the three species included in the study.

More work can be done with the parameterization and validation of wet deposition, especially with respect to the parameterization based on precipitation rates, as e.g. to assimilate measurements of precipitation in the calculations, in order to diminish the uncertainties from the estimation of precipitation.

The model will in the future be incorporated as a part of the NERI's air pollution forecast system, THOR (Brandt et al., 2001a,b and c). The THOR system includes operational air pollution forecasts at different scales - from European scale down to urban street scale and of different species, e.g. ozone, sulphur, nitrogen-oxides, VOC's, etc. Examples of a forecast with the THOR system can be seen at the web page given below.

\section{Further information}

Some visualizations and animations from the DREAM model and the THOR system can be found in the following web pages:

$\backslash$ http://www.dmu.dk/AtmosphericEnvironment/WEPTEL/ DREAM

http://www.dmu.dk/AtmosphericEnvironment/thor.

Acknowledgements. Meteorological data and air measurements concerning the Chernobyl accident and meteorological data concerning the two ETEX-releases have kindly been provided by EURAD. Measurements of deposition from the Chernobyl accident have been obtained through the Radioactive Environmental Monitoring (REM) database at Environment Institute, Joint Research Centre, in Ispra, Italy. This study was funded by the Danish Research Academy and Ris $\emptyset$ National Laboratory. The authors would like to thank sincerely for the financial support. The authors would like to thank the reviewers Dr. Janusz Pudykiewicz and Dr. Roland Draxler for their very useful and constructive comments and recommendations to the manuscript.

\section{References}

ApSimon, H. M., Simms, K. L., and Collier, C. G.: The use of weather radar in assessing deposition of radioactivity from Chernobyl across England and Wales. Atmospheric Environment, 22, 9, 1895-1900, 1988.

Brandt, J., Mikkelsen, T., Thykier-Nielsen, S., and Zlatev, Z.: Using a combination of two models in tracer simulations. Nuclear Safety, Dispersion Prognoses and Consequences in the Environment - a Nordic development and harmonization effort, (Ed) Tveten, U., Tema Nord 1995:544, pp. 85-111, 1995a.

Brandt, J., Mikkelsen, T., Thykier-Nielsen, S., and Zlatev, Z.: Using a combination of two models for tracer simulations. Calculations performed by the National Environmental Institute (DMU) and Ris $\varnothing$ National Laboratory. Report of the Nordic Dispersion/Trajectory Model Comparison with the ETEX-1 Fullscale Experiment. NKS/EKO-4 Intercomparison/Validation Exercise held at Ris $\varnothing$, Denmark, 6-7 June. (Eds) Tveten, U. and Mikkelsen, T., Ris $\varnothing-\mathrm{R}-847(\mathrm{EN})$, NKS EKO-4(95)1, December 1995, pp. 33-48, 1995b.

Brandt, J., Mikkelsen, T., Thykier-Nielsen, S., and Zlatev, Z.: Using a combination of two models in tracer simulations, Mathematical and Computer Modelling, 23, 10, 99-115, 1996a.

Brandt, J., Mikkelsen, T., Thykier-Nielsen, S., and Zlatev, Z.: The Danish Rimpuff and Eulerian Accidental release Model (The DREAM), Phys. Chem. Earth, 21, 5/6, 441-444, 1996b.

Brandt, J., Ellermann, T., Lyck, E., Mikkelsen, T., Thykier-Nielsen, S., and Zlatev, Z.: Validation of a combination of two models for long-range tracer simulations. Proceedings of the $21 \mathrm{st}$ NATO/CCMS International Technical Meeting on Air Pollution Modelling and its Application, Baltimore, Maryland, USA, November 6-10, 1995. Air Pollution Modelling and Its Applica- 
tion XI, Plenum Press, New York., (Eds) Gryning, S. and Schiermeier, F. A., pp. 461-469, 1996c.

Brandt, J., Dimov, I., Georgiev, K., Wasniewski, J., and Zlatev, Z.: Coupling the Advection and the Chemical Parts of Large Air Pollution Models. Lecture Notes in Computer Science. Applied Parallel Computing, Industrial Computation and Optimization, Vol. 1184. Proceedings of the Third International Workshop, PARA'96, UNI-C, Lyngby, Denmark, August 18-24, 1996, (Eds) Wasniewski, J., Dongarra, J., Madsen, K., and Olesen, D., Springer, Berlin, December, pp. 65-76, 1996d.

Brandt, J., Mikkelsen, T., Thykier-Nielsen, S., and Zlatev, Z.: The Danish Rimpuff and Eulerian Accidental release Model (The DREAM) - Results with ETEX-1. NKS/EKO-4(97)1. Report of the second meeting on Nordic dispersion/trajectory model intercomparison with the ETEX-1 full-scale experiment. NKS/EKO4 intercomparison/validation exercise held at FMI, Finland, December 4-5, 1996, (Ed) Tveten, U., Published by FMI, P.O. Box 503, FIN - 00101 Helsinki, Finland, March 1997, pp. 19-32, 1997a.

Brandt, J., Ebel, A., Elbern, H., Jakobs, H., Memmesheimer, M., Mikkelsen, T., Thykier-Nielsen, S., and Zlatev, Z.: The importance of accurate meteorological input fields and accurate planetary boundary layer parameterizations, tested against ETEX-1. In: ETEX Symposium on Long-Range Atmospheric Transport, Model Verification and Emergency Response, 13-16 May 1997, Vienna (Austria), (Ed) Nodop, K., Proceedings. European Commission - EUR 17346 EN, pp. 195-198, 1997 b.

Brandt, J.: Modelling Transport, Dispersion and Deposition of Passive Tracers from Accidental Releases, PhD thesis, National Environmental Research Institute, Roskilde, Denmark. 307 pp, 1998.

Brandt, J. and Zlatev, Z.: Studying Long-Range Transport from Accidental Nuclear Releases by Mathematical Models. In: LargeScale Scientific Computations of Engineering and Environmental Problems. Proceedings of the First Workshop on "Large-Scale Scientific Computations", Varna, Bulgaria, June 7-11, 1997, (Eds) Gribel, M., Iliev, O. P., Margenov, S. D., and Vassilevski, P. S., Notes on Numerical Fluid Mechanics, Vol 62. Printed by Friedr. Vieweg \& Sohn Verlagsgesellschaft, Germany, pp. 136144, 1998.

Brandt, J., Bastrup-Birk, A., Christensen, J. H., Mikkelsen, T., Thykier-Nielsen, S., and Zlatev, Z.: Testing the importance of accurate meteorological input fields and parameterizations in atmospheric transport modelling, using DREAM - validation against ETEX-1, Atmos. Environ., 32, 24, 4167-4186, 1998a.

Brandt, J., Christensen, J., Ebel, A., Elbern, H., Jakobs, H., Memmesheimer, M., Mikkelsen, T., Thykier-Nielsen, S., and Zlatev, Z.: ETEX-1, 2nd phase: Calculations performed by NERI/Ris $\varnothing$ (Denmark) and the University of Cologne (Germany). In: ATMES-II - evaluation of long-range dispersion models using data of the 1st ETEX release. EUR17756 EN, Joint Research Centre, European commission, Office for Official Publications of the European Communities, Luxembourg, (Eds) Mosca, S., Bianconi, R., Bellasio, R., Graziani, G., and Klug, W., pp. 6, 1998b.

Brandt, J., Christensen, J. H., and Zlatev, Z.: Real time predictions of transport, dispersion and deposition from nuclear accidents, Environ. Management and Health, 10, 4, 216-223, 1999.

Brandt, J., Christensen, J. H., Frohn, L. M., and Zlatev, Z.: Numerical Modelling of Transport, Dispersion, and Deposition -
Validation against ETEX-1, ETEX-2, and Chernobyl, Environ. Modelling and Software, 15, 521-531, 2000.

Brandt, J., Christensen, J. H., Frohn, L. M., Palmgren, F., Berkowicz, R., and Zlatev, Z.: Operational air pollution forecasts from European to local scale, Atmos. Environ., 35, Supp. 1, S91-S98, 2001a.

Brandt, J., Christensen, J. H., Frohn, L. M., and Berkovicz, R.: Operational air pollution forecast from regional scale to urban street scale. Part 1: system description, Phys. Chem. Earth (B), 26, 10, 781-786, 2001b.

Brandt, J., Christensen, J. H., and Frohn, L. M.: Operational air pollution forecast from regional scale to urban street scale. Part 2: performance evaluation, Phys. Chem. Earth (B), 26, 10, 825830, 2001c.

Chamberlain, A. C. and Chadwick, R. C.: Transport of iodine from atmosphere to ground, Tellus 18, 226-237, 1966.

Chen, S., Dudhia, J., Gill, D., Guo, Y., Manning, K., Stauffer, D., and Witman, D.: PSU/NCAR Mesoscale Modeling System Tutorial Class Notes. Mesoscale and Microscale Meteorology Division, National Center for Atmospheric Research, pp. 240, 1995.

Christensen J. H.: The Danish Eulerian Hemispheric Model - A three-dimensional air pollution model used for the arctic, Atmos. Environ., 31, 24, 4169-4191, 1997.

De Cort, M., Dubois, G., Fridman, Sh. D., Germenchuk, M. G., Izrael, Yu. A., Janssens, A., Jones, A. R., Kelly, G. N., Kvasnikova, E. V., Matveenko, I. I., Nazarov, I. M., Pokumeiko, Yu. M., Sitak, V. A., Stukin, E. D., Tabachny, L. Ya., Tsaturov, Yu. S., and Avdyushin, S. I.: Atlas of caesium deposition on Europe after the Chernobyl accident, Luxembourg, Office for Official Publications of the European Communities 1998. ISBN 92-828-3140-X, Catalogue number CG-NA-16-733-29-C. EUR 16733, pp. 176, 1998.

Devell: The Chernobyl Reactor Accident Source Term: Development of a Consensus View. CSNI Report, OECD/NEA, Paris, 1995.

Forsythe, W. E.: Smithsonian physical tables. Smithsonian miscellaneous collections, Vol. 120, publication 4169, Published by the Smithsonian Institution, pp. 640-643, 1956.

Grell, G. A., Dudhia, J., and Stauffer, D. R.: A Description of the Fifth-Generation Penn State/NCAR Mesoscale Model (MM5). NCAR/TN-398+STR. NCAR Technical Note. Mesoscale and Microscale Meteorology Division. National Center for Atmospheric Research. Boulder, Colorado, June 1995, pp 122, 1995.

Hanna, S. R., Gifford, F. A., and Yamartino, R. J.: Long Range Radioactive Plume Transport Simulation Model/Code - Phase I. USNRC Division of Contracts and Property Management, Contract Administration Branch, P-902, Washington, DC 20555. Technical report, pp. 121, 1991.

Hass, H., Memmesheimer, M., GeiSS, H., Jacobs, H. J., Laube, M., and Ebel, A.: Simulation of the Chernobyl Radioactive Cloud over Europe using the EURAD Model, Atmos. Environ., 24A, 3, 673-692, 1990.

Klug, W., Graziani, G., Grippa, G., Pierce, D., and Tassone, C.: Evaluation of long range atmospheric transport models using environmental radioactivity data from the Chernobyl accident, The ATMES Report, Elsevier Applied Science, London and New York, pp. 366, 1992.

Landau, L. D. and Lifshitz, E. M., Fluid Mechanics. 2nd edition. Course of theoretical Physics, Volume 6. Pergamon Press plc, Heading Hill Hall, Oxford OX3 0BW, England, pp. 539, 1987. 
Maryon, R. H., Smith, F. B., Conway, B. J., and Goddard, D. M.: The U.K. Nuclear Accident Model, Progress in Nuclear Energy, 26, 2, 85-104, 1991.

Maryon, R. H., Saltbones, J., Ryall, D. B., Bartnicki, J., Jakobsen, H. A., and Berge, E.: An intercomparison of three long range dispersion models developed for the UK meteorological office, DNMI and EMEP. UK Met Office Turbulence and Diffusion Note 234. ISBN: 82-7144-026-08, pp. 44, 1996.

Mosca, S., Graziani, G., Klug, W., Bellasio, R., and Bianconi, R.: ATMES-II - Evaluation of Long-range dispersion Models using 1st ETEX release data. Vol. 1 and Vol 2. Report prepared for ETEX Symposium on Long-range Atmospheric Transport, Model Verification and Emergency Response, Vienna, 13-16 May, pp. 263, 1997.

Nodop, K. (Ed): Proceedings ETEX symposium on long-range atmospheric transport, model verification and emergency response, 13-16 May, 1997, Vienna, Austria, Office for Official Publications of the European Communities, Luxembourg. Printed in Italy, pp. 249, 1997.

Persson, C., Rodhe, H., and De Geer, L.-E.: The Chernobyl Accident - A meteorological analysis of how radionucleides reached Sweden, SMHI/RMK Report No. 55, 1986.

Piedelievre, J. P., Musson-Genon, L., and Bompay, F.: MEDIA An Eulerian Model of Atmospheric Dispersion: First Validation on the Chernobyl Release, J. Appl. Meteo., 29, 1205-1220, 1990.

Pudykiewicz, J.: Simulation of the Chernobyl dispersion with a 3-D hemispheric tracer model, Tellus, 41B, 391-412, 1989.

REM: Radioactive Environmental Monitoring, User manual. Joint Research Centre, Environment Institute, EUR 14222, Commission of the European Communities. http://www.ei.jrc.it/ie/ projects/REM/; http://rtmod.ei.jrc.it/rem/

Seinfeld, J. H.: Atmospheric Chemistry and Physics of Air Pollution. Printed by John Wiley \& Sons, Inc., New York, pp. 738, 1986.

Seland, Ø, van Pul, A., Sorteberg, A., and Tuovinen, J.-P.: Implementation of a resistance dry deposition module and a variable local correction factor in the Lagrangian EMEP model, EMEP/MSC-W, Report 3/95, July 1995, pp. 57, 1995.

Sehmel, G. A.: Particle and gas deposition: a review, Atmos. Environ., 14, 983-1011, 1980.

Sheih, C. M., Wesely, M. L., and Hicks, B. B.: Estimated dry deposition velocities of sulphur over the eastern United States and surrounding regions, Atmos. Environ., 13, 1361-1368, 1979.

Slinn, S. A. and Slinn, W. G. N.: Predictions for particle deposition on natural waters, Atmos. Environ., 14, 1013-1016, 1980.
Spiegel M. R.: Theory and problems of statistics 2/ed. Schaum's outline series, McGraw-Hill INC, New York, pp. 504, 1992.

Sundqvist, H.: Prediction of stratiform clouds: Results from a 5-day forecast with a global model, Tellus, 33, 242-253, 1981.

Verver, G. H.L. and De Leeuw, F.A. A. M.: An operational puff Dispersion model, Atmos. Environ., 26A, 17, 3179-3193, 1992.

Valkama, I. and Pöllänen, R.: Transport of radioactive materials in convective clouds, In: Proceedings of the 14th International Conference on Nucleation and Atmospheric Aerosols, Helsinki, August 26-30, 1996, (Eds) Kulmala, M. and Wagner, P. E., pp. 4, 1996.

Valkama, I., Salonoja, M., Toivonen, H., Lahtinen, J. and Pöllänen, R.: Transport of Radioactive Gases and Particles in the Chernobyl Accident: Comparison of Environmental Measurements and Dispersion Calculations. International Atomic Energy Agency. International Symposium on Environmental Impact of Radioactive Releases, Vienna, Austria, 8-12 May 1995. IAEASM-339/69. pp. 10, 1995.

Voldner, E. C., Barrie, L. A., and Sirois, A.: A literature review of dry deposition of oxides of sulphur and nitrogen with emphasis on long-range transport modelling in North America, Atmos. Environ., 20, 11, 2101-2123, 1986.

Waight, P., Métivier, H., Jacob, P., Souchkevitch, G., Viktorsson, C., Bennett, B., Hance, R., Kumazawa, S., Kusumi, S., Bouville, A., Sinnaeve, J., Ilari, O., and Lazo, E.: Chernobyl Ten Years On. Radiological and Health Impact. An Assessment by the NEA Committee on Radiation Protection and Public Health, November 1995, OECD Nuclear Agency, http://www.nea.fr/, pp. 74, 1995

Wallace, J. M. and Hobbs, P. V.: Atmospheric Science. An introductory survey, Published by Academic Press, INC. (London) LTD, 1977, pp. 467, 1977.

Warneck, P.: Chemistry of the natural atmosphere, Academic Press, page 390, 1988

Weast, R. C. and Astle, M. J., (Eds.): CRC handbook of chemistry and physics. 60th edition, CRC Press, Inc., printed in the USA, 1980.

Wesely, M. L. and Hicks, B. B.: Some factors that affect the deposition rates of sulfur dioxide and similar gases on vegatation. $\mathbf{J}$. Air. Pollut. Control Ass., Vol 27, pp. 1110-1116, 1977.

Zlatev, Z.: Computer Treatment of Large Air Pollution Models. Environmental Science and Technology Library. Vol. 2, Published by Kluwer Academic Publishers, P.O. Box 17, 3300 AA Dordrecht, The Netherlands. pp. 358, 1995. 